\title{
The effects of preschoolers' goal setting, decision making, and self-recording on academic achievement
}

\author{
Keri Smith \\ West Virginia University
}

Follow this and additional works at: https://researchrepository.wvu.edu/etd

\section{Recommended Citation}

Smith, Keri, "The effects of preschoolers' goal setting, decision making, and self-recording on academic achievement" (2010). Graduate Theses, Dissertations, and Problem Reports. 686.

https://researchrepository.wvu.edu/etd/686

This Thesis is protected by copyright and/or related rights. It has been brought to you by the The Research Repository @ WVU with permission from the rights-holder(s). You are free to use this Thesis in any way that is permitted by the copyright and related rights legislation that applies to your use. For other uses you must obtain permission from the rights-holder(s) directly, unless additional rights are indicated by a Creative Commons license in the record and/ or on the work itself. This Thesis has been accepted for inclusion in WVU Graduate Theses, Dissertations, and Problem Reports collection by an authorized administrator of The Research Repository @ WVU. For more information, please contact researchrepository@mail.wvu.edu. 
The Effects of Preschoolers' Goal Setting, Decision Making, and Self-Recording on Academic Achievement

\title{
Keri Smith
}

Thesis submitted to the College of Human Resources and Education at West Virginia University in partial fulfillment of the requirements for the degree of

\author{
Master of Arts \\ In Educational Psychology \\ With an emphasis in Child Development and Family Studies \\ Barbara G. Warash, Ed.D, Chair \\ Dan Hursh, Ph.D. \\ Amy Root, Ph.D.
}

Department of Technology, Learning, and Culture

Morgantown, West Virginia

2010

Keywords: negotiation, initiation, planning, self-recording, goal achievement

Copyright 2010 Keri B. Smith 


\begin{abstract}
The Effects of Preschoolers’ Goal Setting, Decision Making, and Self-Recording on Academic Achievement
\end{abstract}

Keri B. Smith

This study investigated to see if preschool children could determine their own achievable goal and use self-recording of the step by step instruction to achieve the goal. In addition, children presented their goals to their peers. To investigate the effect of self-recording of step by step instruction, two individual case studies were completed in experiment one. A multiple baseline across participants was used in experiment two to measure three separate children's achievement during baseline and intervention of self-recording and step by step instruction. It was found that over $50 \%$ of the children could state their own achievable goal. It was also found that children's academic performance increased when self-recording their own progress. 


\section{Acknowledgement}

I would like to show my gratitude to my advisor and committee chairperson, Dr. Barbara Warash, whose encouragement, support, and guidance I attribute the level of my Masters degree. Along with my committee chairperson, I would like to thank fellow committee members Dr. Dan Hursh and Dr. Amy Root for their guidance and assistance during the construction of my thesis. Also, I would like to thank Melissa Workman for her continued support in carrying out the research of this study. Finally, I would like to thank my family and friends who have given me the confidence and encouragement to succeed in both school and life. 
Table of Contents

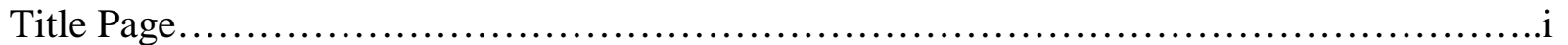

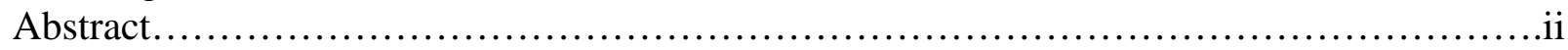

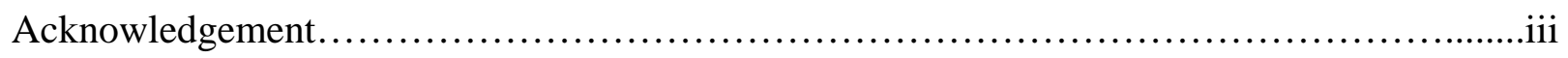

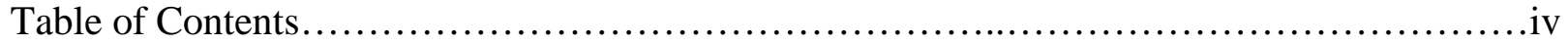

CHAPTER I

Introduction/Review of Literature.......................................................

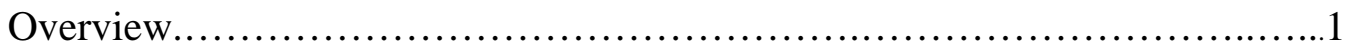

Decision Making \& Planning..................................................2

Self-Recording............................................................. 9

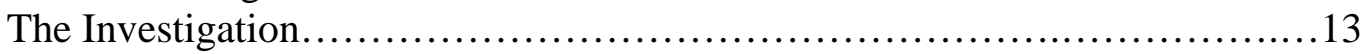

Design .......................................................... 14

CHAPTER II

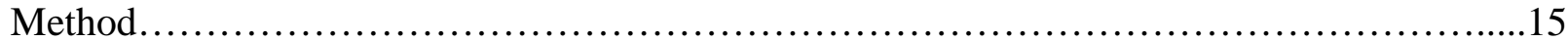

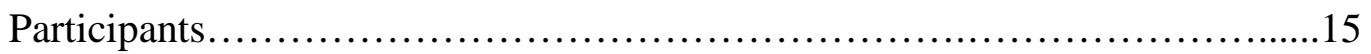

Setting.................................................................. 15

Behaviors, Measures, \& Accuracy .....................................17

Procedure............................................................... 20

\section{CHAPTER III}

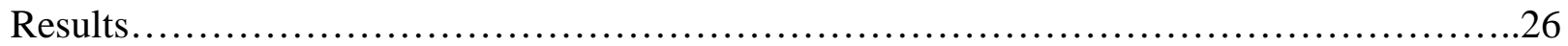

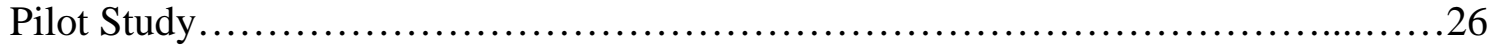

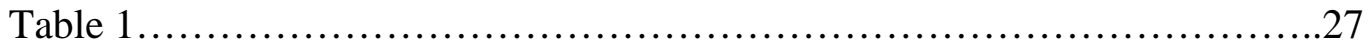

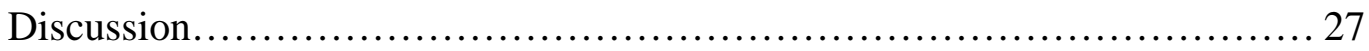

CHAPTER IV

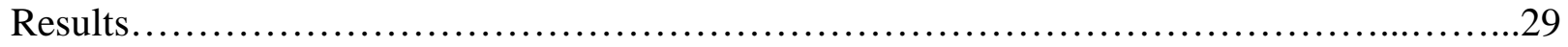

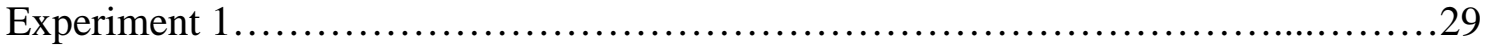

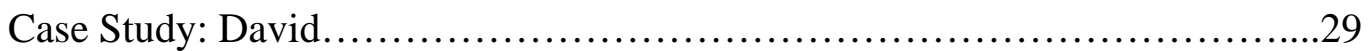

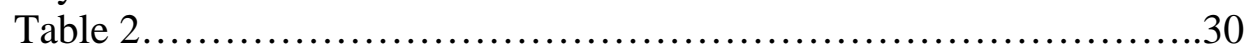

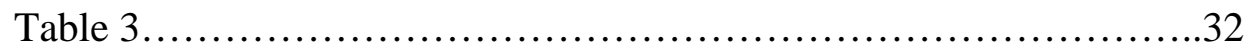

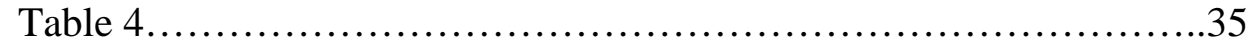

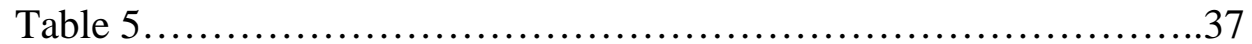

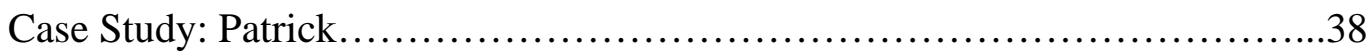

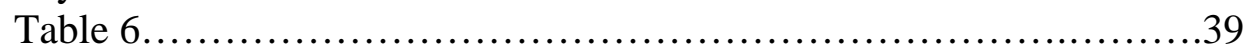

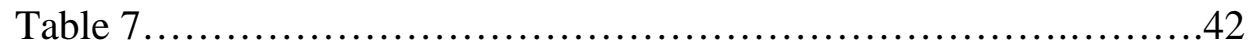

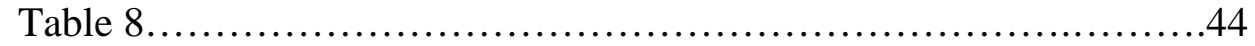

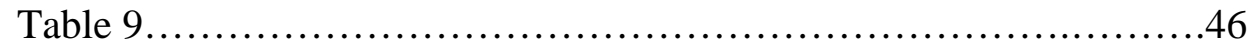

Data Analysis: Case Studies..........................................47

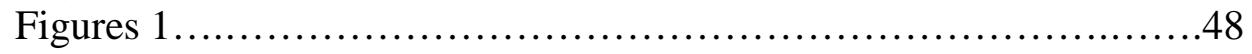

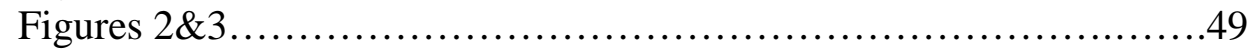

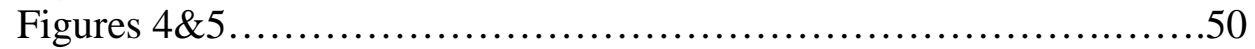

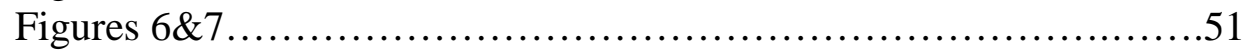




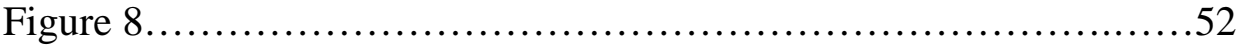

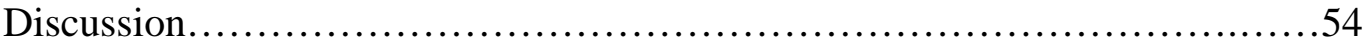

\section{CHAPTER V}

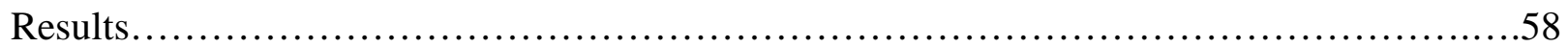

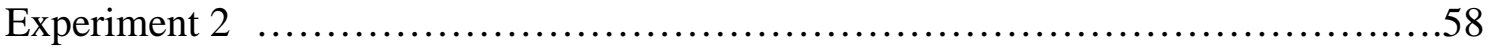

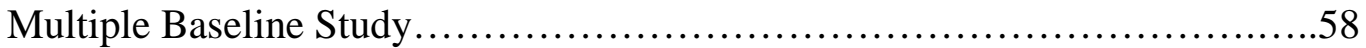

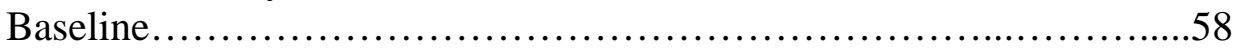

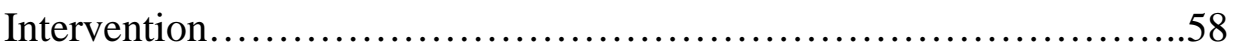

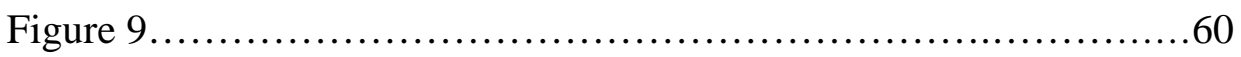

Data Analysis: Multiple Baseline Study ....................................61

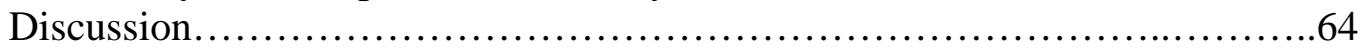

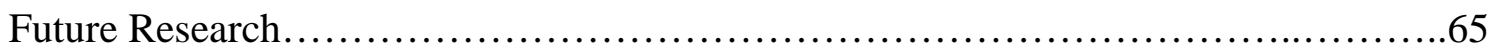

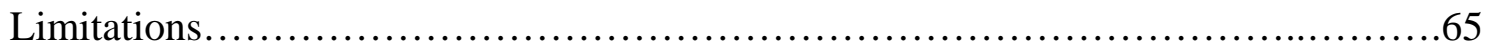

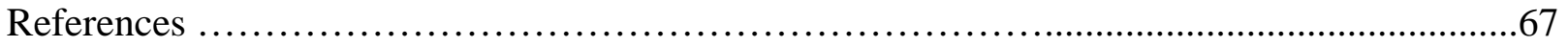

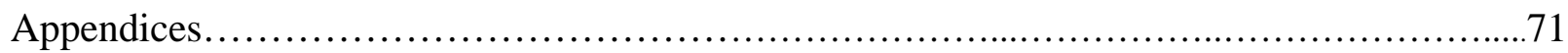

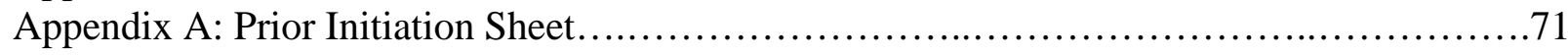

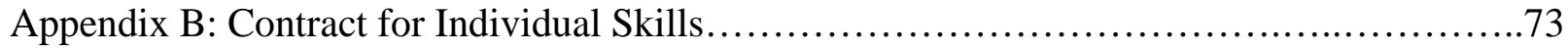

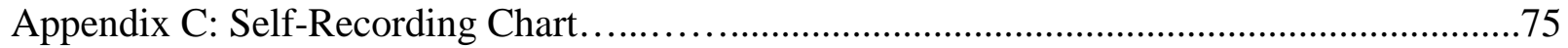

Appendix D: Initiation/Outcome Chart.................................................

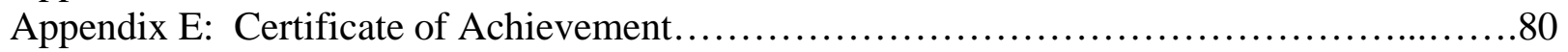




\section{Chapter I}

\section{Introduction/Review of Literature}

\section{Overview}

Many preschools have changed from the traditional programs that were in existence solely for young children to have the opportunity to socialize and play with peers. As more is learned about young children and their capabilities through current brain and other scientific research (Marcovitch, 2008), more progressive types of curricular activities are being implemented to accommodate the young child's advanced intellect as well as to help children develop life skills needed to be competent learners. In addition, executive function is an area that is now being addressed in the early childhood literature with its emphasis on life skills such as working memory, planning, and self-monitoring. Executive function refers to includes "selfregulation, planning, behavior organization, cognitive flexibility, response inhibition, and resistance to interference (Albertson \& Shore, 2008). Socialization is still a major focus in a preschool program with play as the major vehicle for teaching young children, but the preschool content has changed to not only address state preschool content standards and regulations but to help young children learn to focus and regulate their own behavior. Content standards for young children exist in all states with West Virginia as one state who had developed learning criteria for preschool children (West Virginia Early Learning Standards Framework, 2004). The 21st century educational skills (2008) have also influenced early childhood programs. These skills include teaching and learning that combines with student outcomes with innovative support systems to help students master the multi-dimensional abilities required of them in the $21 \mathrm{st}$ century. These skills include life skills such as taking initiative and self-direction (pp. 1-6). Standards and an appropriate curriculum must be addressed in preschool programs to fulfill the 
requirements of being a West Virginia Universal Pre-K program. The West Virginia University Nursery School (Nursery School) is one of the West Virginia Universal Pre-K programs and therefore adheres to all state standards as well as the recommendation for the $21^{\text {st }}$ century educational skills. At the Nursery School, the West Virginia content standards are met through the use of the Creative Curriculum (Dodge, 2002), one of the state approved curricula and is supplemented by additional innovative projects developed through curricular research at the Nursery School.

\section{Decision Making and Planning}

Young children planning and making their own decisions seems to be a sophisticated task for four and five- year- olds but it has been explored. One such research project at the Nursery School that was relevant to this study was the idea of young children making their own decisions about the activities they wanted to choose to do while at school (Warash, 2001). Warash developed a pictorial contract system which encourages children to participate in activities through decision-making and self-direction. The contracts are used daily to keep children on track with teacher and child-directed activities and gives children a visual representation of their choice opportunities. Most children want to do activities that interest them; therefore having children circle the centers or student-teacher planned lessons, represented on the contract helps them to make purposeful decisions about their activities. Once a center is completed, the teacher writes a specific explanation of what the child accomplished in that particular activity. Children use these contracts to measure the number of activities completed and to reflect on their productivity.

Contracts are also a beneficial tool for parents to develop an understanding of the types of activities provided during the time their children are at the Nursery School. Because children 
take the contracts home, they offer parents an opportunity to engage their child in a conversation about their school day. This home school connection is supported by such groups as The National Association for the Education of Young Children (NAEYC). NAEYC is an association dedicated to improving the well-being of all young children, with particular interest in the development and quality of education (Hyson, 2003). One of NAEYC's standards relates to building family and community relationships with an emphasis on "involving all families in their children’s development and learning” (p. 6). According to Arnold, Zeljo, and Doctoroff (2008), parents who are involved in their children's preschool may be more knowledgeable about school activities and are also more likely to "help build positive relationships between children and their teachers, foster positive feelings about school and generally support children’s social and academic development” (2008, p. 77).

The implementation of contracts, at the Nursery School strengthened the democratic environment by encouraging children to participate in their own learning. This approach has been very successful because it allows children to think about their choices before they commit to an activity and gives them opportunities for achievement in activities that are of interest to them (Warash, 2001). A similar approach that is widely used is High Scope which places a focus on children making decisions. This curriculum uses a plan-do-review system which has children plan, carryout, and then recall their work. High Scope is used in programs all around the world with its premise that children learn best by establishing and pursuing their personal interests and goals. Children in High Scope settings are encouraged to make choices about materials and activities throughout the day. As they pursue their choices and plans, children explore, ask and answer questions, solve problems, and interact with classmates and adults. In this kind of environment, children naturally engage in "key experiences" and activities that foster 
developmentally important, yet individualized skills and abilities (Hohmann \& Weikart, 1995). The Nursery School contract system takes it one step further in that children take home the contract to serve as a prompt for parents to engage their children in a conversation.

Implementing a democratic classroom is not a new idea. John Dewey (1916) was at the forefront of advocating an environment that provides opportunities for children to make decisions. He described a democratic classroom as being the only type in which individuals are able to grow and socially participate in a manner that allows for the realization of their unique interests and gifts (Dewey, 1916). For a democratic classroom to flourish, it requires individuals to maximize their potential in activity with others and according to Dewey, "perpetuate the duality of mind and action and of the individual and society (Dewey, 1916, p. 236).”

Another project at the Nursery School that contributes to children taking responsibility for their learning is the scrapbook project. The scrapbook project adopted by the Nursery School in 1986 (Warash \& Kingsbury, 1988) was developed so children could plan and create stories in a creative way. This project gives children an opportunity to use their imagination to develop a story. The teacher uses prompting and questioning to guide the child's thought. One of the most important aspects of this project is that children are encouraged to revisit their stories and make changes before continuing on to "act” them out with peers. Children, just as adults, need to be able to make changes in their work when it is something that is meaningful to them. As with contracts, when children revisit their work they are more likely to develop mental functions associated with higher-order thinking skills (Moran \& Jarvis, 2001). This practice of editing is encouraged not only in the scrapbook project but in other activities that children do.

Contracts and scrapbooks were the impetus for future curriculum areas that encourage young children to take responsibility in their learning and to make good decisions. For example, 
the paper doll project was initiated a few years ago. The paper doll project was an inexpensive way for children to create their own personal paper doll including various outfits and accessories. Children used the dolls in pretend situations which encouraged interaction among children. In this project, it was found that children took pride in their dolls because they had an investment in the outcome. They spent time cutting and creating their doll and clothes and therefore respected their own work. Warash found that when children have an investment in their projects they are more likely to respect and use the product. This project allowed children to become engaged and absorbed as they continued to learn (Warash, 2004).

When young children plan, they start with a personal intention, aim, or purpose (Warash, 2001). Depending on their age and capacity to communicate, they express their intentions in actions, gestures, or words (Whittin, 1997). When children participate in the planning process each day, they grow accustomed to indicating their intentions before acting them out (Hohmann \& Weikart, 1995). When children make plans, they participate in a variety of mental tasks. Hohmann and Weikart (1995) discuss the components of the planning process as the following: a) Establishing a problem or a goal - During this stage, children decide what they want to learn about based on their interests. b) Imagining and anticipating actions - Children during this stage imagine something happening that has not yet occurred so they begin to understand that their actions can make it happen. c) Expressing personal intentions and interests - Children’s own intentions and interests drive them in achieving their goal. d) Shaping intentions into purposes When children plan they develop intentions into purpose and with adult support at planning time, children can formulate such purposeful plans. e) Deliberating - Children may initially want to plan to be successful at achieving their goal, but later become involved in the learning process. f) Making ongoing modifications - Although children are able to plan themselves, they may modify 
their plans as they go. Children often construct new ideas once they encounter unforeseen obstacles that may come between them and their goals (pp. 168-170).

Dewey (1938) also commented on the importance of role playing and reflecting on play for development and learning. This view revolves around children making good decisions in goal-directed activities and the child's participation in the child's learning process. Another curriculum with an emphasis on planning and following through with ideas and goals is the Tools of the Mind curriculum. This Vygotskian approach has been in the forefront of preschool research. Its emphasis is on executive functions and its relationship to the child's regulatory behavior of planning and following through are necessary skills for success in later schooling. Elena Bodrova and Deborah Leong (2001) developed this Vygotskian curriculum of early childhood to better understand the cognitive development of young children. One aspect of this Vygotskian approach as presented by Bodrova and Leong (2000) is described as the child developing abstract meaning separate from the objects in the world, which is a critical feature in the development of higher mental functions. Bodrova (2000) indicates that in a Vygotskian classroom, children use language and other forms of representation such as drawing, scribbling, and eventually writing to plan their activities. Vygotsky regarded language as a critical bridge between the sociocultural world and individual mental functioning that is a significant milestone in children’s cognitive development (Berk \& Winsler, 1995). Vygotsky understood that language was a vehicle for not only representing the world, but expanding development and learning and this was also considered the beginning of self-control and self-regulation (Vygotsky, 1978).

To further extend the child’s opportunity to make good decisions and plan with intent, the Nursery School began the Vygotskian method of “play plans.” With this method, children use 
language and other forms of representation to plan their activities. Play plans were implemented to assist children in thinking ahead and following through with the plans. According to Bodrova and Delong (2000) the idea is that young children plan their play using language as a vehicle for developmental growth. Vygotsky (1978) viewed the idea of planning play as the best means for children to reach outcomes. If this is true, then children planning their own goals would seem to be an appropriate way for them to accomplish a skill.

At one time the WVU Nursery School operated primarily with a constructivist point of view with very little crossover into other theories. Recent explorations have shown that a merging of philosophies (Warash, Curtis, Hursh \& Tucci, 2008) can be beneficial to children and their individual needs. When describing teaching at the early childhood level; theories should not be practiced in isolation, but should converge and be implemented in a variety of ways as demonstrated in the Reggio Emilia approach. The Nursery School utilizes developmentally appropriate practice (DAP) with significant applications of the theories of Vygotsky (1978), Skinner $(1948,1953)$ and Piaget (1962). This theoretical blend of ideas combined with the principles of the Reggio Emilia approach are used to engage children in long-term projects with 'scaffolding ' as the tool used to help children reach their developmental potential. Along with the converging of theories, there have also been conflicting views regarding planning and use of daily experiences (Warash, Curtis, Hursh, \& Tucci, 2008). Malaguzzi (1998) who was the founder of the Reggio Emilia approach argued that young children were capable of making meaningful decisions regarding their learning and were able to plan and coordinate activities they wanted to learn. In contrast, Piaget $(1937,1962)$ believed that children learned through exploration and were incapable of making such abstract decisions regarding their learning at an early age. Reggio Emilia emphasizes children’s potential, rather than their weaknesses, which 
develops independent learners through direct instruction and individualized planning (Malaguzzi, 1998). Such instruction allows children to develop to their full potential; therefore children at an early age are more competent to make such meaningful decisions than originally thought by Piaget. Young children can make decisions and follow through as shown when children were given a pictorial contract (Warash 2001). Simply by respecting children's right to know their choices by displaying the choices available gives young children the information to make a decision.

Lysyuk (1998) found that children could take part in their own learning. He completed a study on the development of productive goal setting with young children. Productive goals are those that have an expected outcome but can be achieved by changing something in the environment. For example, if a child decides to represent a house, then this would be the goal but it could be attained by various means such as building, drawing, clay modeling etc. His purpose was to explore children's ability to develop productive goals independently, the developmental course of the ability to relate different productive goals, and whether the emergence of productive goals will precede the productive outcomes or if it would occur in reverse order. He found that children from the age of three have the ability to set productive goals and to achieve the outcomes. After the age of three, Lysyuk suggests that important changes in development take place and the number of children who do not show productive goal setting decreases. He concluded that goals do not develop independently from activities. It is at the moment when activity ends that processes are activated that induce the emergence of productive goal setting.

To support children's planning effectively, adults must be aware of children's personal interests, and ways that they can incorporate the planning process into a daily routine. According to Hohmann and Weikart (1995), adults must focus with children on one-to-one 
planning conversations. This allows for a more 'individualized' approach to learning. Adults should be there to guide, but the children should be able to take charge once they are familiar with the planning process. Brown (2008) noted in her study that purposeful teaching techniques are beneficial for children in planning and evaluating their progress. These include: Helping children set or accept and record individualized goals; teaching, modeling, and planning in ways the children may progress towards goals, showing the children evidence of their progress with carefully kept records, and helping children celebrate goal achievement and attribute positive feelings to their own efforts.

So why is planning important for young children? By planning, children come to rely on their own capabilities to make good choices and decisions. Planning gives children the opportunity to experience the relationship between their intentions and their actual actions. According to Epstein (2003), 'planning is choice with intention' and making a choice with the added ingredient of intentionality allows effective mechanisms for developing thinking skills to emerge. By planning, children are committing themselves to be involved in a task that they believe is important to them. Therefore, they are allowing appropriate challenges to stimulate and support their emerging capabilities (Hohmann \&Weikart, 1995). Children may also enhance their predictive and analytical abilities, language skills, and develop a sense of responsibility for themselves and the choices they make. Planning and reflection is a useful evaluation tool that helps with the achievement and fostering of goals (Epstein, 2003).

\section{Self-Recording}

Little research has been conducted on young children recording progress on their own work as Lillian Katz (2009) alludes to in her new book, Intellectual Emergencies. Katz stresses the importance of children evaluating their own progress on their work. Meeting with children 
individually to summarize the skills they have been working on is a valuable experience. One kindergarten study (Moxley \& Studwell, 1984) was completed on children self-recording their own progress in a naturalistic setting. The skills were ones that the teacher had the children work on as part of the kindergarten curriculum. They included such skills as numerals, ABCs, birthdays, addresses, capital letters, small letters, left/right, and rhyming. The teacher kept records on the children's performance before the children began keeping their own records. Each month the teacher had a different skill for children to self-record. The rate of the children's achievement of the skills increased dramatically when the children began to keep and display their own records. Children kept track of their progress two weeks or more after each child had first accomplished the task. In this study of 23 children, all the participants increased their achievement in every skill. Once a skill was complete, children were told they could show mastery of the achieved skills in front of the group during circle time or to the teacher personally and once the skill was achieved, they could move onto new self-recordings. The results showed that the rate of the children's achievement increased significantly when the children selfrecorded. In addition, teachers can use the self-recorded information as a detailed assessment of a child's progress and revise instruction accordingly. This type of evaluation system is an intrinsic motivator for children as they monitor their own progress with the child's name on it showing all skills introduced. Moxley and Studwell (1984) noted that this study provided several benefits in aiding children's academic achievement; these benefits include self management skills, responsibility for own learning, and direct participation in evaluating their own progress..

Young children can make decisions, as well as, self-record their own progress when working with the teacher on a skill (Moxley, Rupich, Studwell, \& Gibson, 1983). Charting one’s own progress seems such a logical thing to do but so many times it is the teacher who records the 
progress leaving the child out of the loop. However, as Moxley et al. (1983) emphasized, it would be much easier if records were "naturally" kept by the children themselves as part of their learning experiences. There are many techniques used to allow children to self-record their own progress. A form may be useful in keeping children organized which allows for children to keep track of their self-recording marks. However, according to Whittin (1997), unlined paper is also helpful for children recording information because their data is then free to be displayed in various ways. Moxley et al. (1983) note that children can collect tokens, stickers, or use their own markings such as check marks for these recordings. Their study indicates that curriculum areas that self-recording can be implemented with include writing, reading, math, science, social studies, and creative expression. Children like recording their own progress when they are learning a new skill such as numbers and letters. According to Whittin (1997), self-recording seems to produce a higher performance rate than if the records were kept solely by the teacher.

As reported in Moxley and Studwell's (1984) study, children were able to show to the class their mastery of skills. Whittin (1997) also noted that it is crucial that children have the opportunity to share their projects and data visually with their peers and discuss their individual interpretations of what they have accomplished to evaluate their progress. On the contrary, young children may possess developmental limitations that may constrain their ability to compare past and present performance, but they can assess what they have learned if they have appropriate language for describing their achievements (Brown, 2008).

Children who are identifying their progress are also more likely to repeat the process due to self-reinforcement (Skinner 1948). Reinforcers are stimuli that increase the probability of the behavior they follow. Primary reinforcers are those reinforcers that are necessary for survival (food, water, etc.), where as conditioned reinforcers are learned and are acquired (tokens, 
positive comments, etc.). Positive reinforcement increases behavior and increases the tendency to make that same response again. Skinner also said it is important for adults to provide positive reinforcement if they want to repeat the behavior (1948). Skinner $(1948,1953)$ developed the theories of functional analysis of behavior and operant conditioning. His functional analysis of behavior consists of (a) what defined the beginning and end of the behavior, (b) what stimulus came before the behavior, and (c) what consequence came after the behavior. This system evaluates explanation, summary, and prediction. He believed that there were two principles that drive operant conditioning, a response, which is an action or behavior that the action does and a reinforcing stimulus, which is the consequence that follows the response and increases the probability that the same response will be emitted in the future (Skinner, 1948).

Wheldall and Panagopoulou-Stamatelatou (1991), investigated the effects of pupil selfrecording of on-task behavior in primary school classes with children eight to eleven years of age. The target children were selected by their teacher on the basis of the fact that they were believed to be wasting a lot of time in off-task behaviors. Self-recording was introduced successively to the three classes at one week intervals. Students were regarded as on-task when they made eye-contact with the teacher, were listening, looking up words in a dictionary, raising their hand, and so on. Self-recording was used as an intervention strategy for the whole class in an attempt to establish appropriate antecedents so that children could concentrate better within a quieter environment and to provide effective consequences for appropriate behavior. Once selfrecording was implemented more appropriate behaviors were noticed.

The impact of integrating a behavioral approach with one that is very entrenched in developmentally appropriate practice has opened the door to other initiatives. This study went beyond giving children the choice of activities and concentrated on whether or not young 
children could determine their own goals and accomplish the goal by self-recording their own progress. Previous research (Moxley \& Studwell, 1984) suggested that kindergarten children can make progress when they use self-recording on skills the teacher wanted them to learn. Previous research studies also indicated that young children can make decisions (Brown, 2008, Lysyuk, 1998 \& Warash, 2001) and they can plan (Hohmann \& Weikart, 1995). Can these skills be combined so that children can accomplish a self-determined goal through self-recording.

\section{The Investigation}

The questions of this current study were two fold. First, can preschool children determine their own achievable goal? Second, can self-recording of the step by step instruction of the goal be an effective strategy for achieving this goal? In essence, it is hypothesized that young children, who choose an appropriate goal (deciding and planning) and self-record their own progress with the teacher breaking the goal into steps, will achieve higher academic performance. In this study, academic performance will be defined as goal achievement and achievement carried out further in daily classroom activities. In an attempt to answer these questions, all children in the four-year-old class were given the opportunity to set a goal in a pilot study. To investigate the effect of self-recording of step by step instruction, two individual case studies were completed in experiment 1. In addition, a multiple baseline across participants was used in experiment 2 to measure three separate children's achievement during baseline and intervention of self-recording and step by step instruction. 


\section{Design}

A pilot study was used during the initial phase of the study. This was conducted to see if children could determine an achievable goal. If a child was not able to state an achievable goal, the goal was negotiated among the researcher, observer, and child.

During experiment 1, case studies were used to add in-depth information on the two participants. The case studies introduced the two children and broke down each of their achievable goals through the step by step instruction given by the researcher. Detailed information was added on their self-recordings and their final presentations.

The design option identified for experiment 2 was a multiple baseline across participants. This design was chosen to compare three separate children to the original study to see if goal achievement was improved by self-recording and step by step instruction. Intervention took place only after a stable baseline was established for each child and at different points in time. Follow-up took place by presenting to classmates and thereafter written daily in their play plans. During baseline and intervention, the child's peers continued with normal daily activities while the intervention was implemented. 


\section{Chapter II}

\section{Method}

\section{Participants}

Data were collected from January 2009 to May 2009 in the four-year-old class of the WVU Nursery School. There were 20 children enrolled in the afternoon session who participated in the pilot study. This part of the study was conducted to see if children could determine an achievable goal. The children's chronological ages ranged from 49 months to 61 months. During experiment 1, data were collected from two children who participated in the pilot study and returned to the WVU Nursery School the following year. These two children were chosen because they participated in experiment 1 and were returning to Nursery School in August 2009. Data on these two boys were collected from September - December, 2009. These two boys, who were faternal twins, were typically developing and constituted the individual case study of the project. When they participated in January 2009 they were 53 months old. During the next part of the study in September, they were 61 months. These two participants attended the Nursery School since they were 37 months old; therefore they were familiar with the facility, teachers, and curriculum. For experiment 2, three additional typically developing children were assessed from January to March 2010. There were two girls at 61 and 63 months of age and one boy who was 58 months old when first baseline observations took place in January. For this

study, the researcher was the graduate assistant conducting the research and the observer was the head teacher assisting the researcher.

\section{Setting}

The initial phase of the study took place in the former West Virginia University Nursery School and the subsequent case studies took place at the new Nursery School/Child Development Laboratory School located in Morgantown, WV. Nursery School has a 
combination of child-directed activities and teacher planned activities in literacy, math, science, social studies, and the arts. It is designed to provide observational and practicum experiences for West Virginia University students. There are a total of five staff members daily, with two staff members present at all times. The Nursery School schedule consists of two sessions that are held on a daily basis in which twenty three-and four-year olds attend the morning class and twenty four- and five-year-olds attend the afternoon class. The project for this study took place in the afternoon session which operates Monday through Friday from 12:45PM to 4:30PM.

During the pilot study and experiment 1 , the researcher and observer met with each child in the afternoon session, during free play between 1:00-2:00 or 3:20-4:00, or during rotating centers between 2:15-3:10. The individual meeting lasted approximately 5-10 minutes. Individual meetings with children began in January, 2009 to determine a goal and continued until children were ready to re-negotiate a new goal/skill. Individual meetings were once again started during the new school year in September and the same time frames were used. The location of the individual meetings took place in the Nursery School office at a round table with three chairs. This table is separated from the director, head teacher, and graduate assistant desks. The walls surrounding the main entrance of the office are large windows that look out into the classroom. There are three other windows on the other side of the office. This location is quiet and free of traffic flow from other children. The dimensions of the office are $12^{\prime} 71 / 2^{\prime \prime} \mathrm{W}$ x $21^{\prime} 2^{3} / 4$ ” $\mathrm{L}$, with a total of 250.4 sq. $\mathrm{ft}$.

Individualized step by step instruction with child and researcher/observer took place during free play between 1:00-2:00 and 3:20-4:00, or during rotating centers between 2:15-3:10. Each child met individually with researcher/observer for 5-7 minutes, 2-3 times per week to work on their goal. There were two main locations for this part of the study. The office was the 
main location for most of the work between the researcher and child. This quiet space allowed for one-on-one instruction with child and researcher. Other locations were used in the school when the goal/skills dictated the need. For example, the table in the art area was used if a child set his/her goal as sculpting in clay. This location was used as an alternative to the office when clay and paint activities were conducted. The art area consisted of one rectangular table measuring 3’8” L x 30” W, an easel, shelves full of paper, markers, and paint, a sink, and a drying rack.

In addition to working towards their goals, children presented their accomplished goals to their classmates. The presentations took place in the main meeting area in the classroom. This area was comprised of three tiers of steps which were used as the seating area. This area was enclosed by walls that provided a barrier so sound would not escape. There was one entrance to the meeting area and it was located in the front. Children sat on the tiered steps and the presenter sat on a small child-sized chair at the bottom in the entrance way.

\section{Behaviors, Measures, and Accuracy}

This study used data that was collected for 14 months at the Nursery School. One of the target behaviors of this study was to investigate whether preschool children could state an appropriate goal that was achievable for them. Children were asked what they wanted to learn while working individually with the researcher at the West Virginia University Nursery School. Examples of appropriate goals that children might want to learn included printing their name, practice holding a pencil, learning to identify the alphabet, etc. These examples were stated to the children to give them an idea. The observer and the researcher were present to record if 1) a child stated an appropriate goal, 2) a child did not state an appropriate goal, or 3) if there was a need for the child and researcher to negotiate an appropriate goal (for example: if a child stated 
that he or she wanted to learn to read, but did not know the alphabet, then this would be considered an inappropriate goal for this child). In this case, the researcher and observer intervened to help the child determine a goal that was achievable. The intervention in this part of the study was the negotiation between the child and researcher for an achievable goal. Measurement was taken by the researcher and the observer throughout observations on a separate tally sheet (see Table 1). The researcher and observer wanted to see if each child could state an achievable goal that he or she wanted to learn. For the purpose of this study, goal setting referred to children stating an educational goal that was achievable for the child.

Ascertaining the highest level of agreement was very important, thus agreement was assessed using two different calculations, a point-by-point ratio and kappa. The point-by-point ratio assessed inter observer agreement by comparing the number of agreements and disagreements between the researcher and observer. To calculate the point-by-point ratio, the total number of agreements plus the total number of disagreements were divided into the total number of agreements of behavior occurrence for an overall agreement ratio. . An overall pointby-point ratio of .923 , with a range of .91 to .94 , was reached well exceeding the .80 goal to be considered reliable. Kappa corrected for chance agreement and subtracting the number of possible chance agreements from the point-by-point total completed computation of this statistic. Checks on agreement were calculated and needed to reach a minimum level of $80 \%$ for each agreement type to be considered adequate (Kazdin,1982). The kappa coefficient came to a total of .91 with a range of .90 to .93 , again surpassing the .80 benchmark, needed to be considered reliable.

The observer and researcher tallied across children whether the child set an appropriate goal, did not set an appropriate goal, or if the child and researcher negotiated an appropriate goal. 
An agreement between the researcher and observer was the agreement that the child did or did not choose an appropriate goal. Both the researcher and the observer had experience with the children and typically had observed the children's educational capabilities. The tally sheet included name, date, and three sections. The sections included whether the child sets an appropriate goal, does not set an appropriate goal, or if the child and researcher negotiated an appropriate goal. If the child stated a non-achievable goal then the researcher, observer, and child negotiated an appropriate goal (see Table 1).

The second target behavior for the next phase of the study was once an achievable goal was established and the researcher specified steps of the goal, could the child achieve the goal by self-recording his/her progress? Two returning children from the previous semester were used in the study. These two children specified four individual goals. Baseline for the self-recording during these four goals was determined through naturalistic observation. The classroom activities normally conducted at the Nursery School used global goals and objectives of the Creative Curriculum (Dodge, 2002). These objectives included, controls small muscles in hands, explore cause and effect, and recognizes patterns and can repeat them, and so on. The Creative Curriculum shows how to incorporate developmentally appropriate practice in preschool programs and is particularly designed for early childhood programs serving children 3-5 years of age. "The Curriculum describes each subject area and shows how to teach it in ways that support children's academic progress while respecting the way they grow and develop” ( p. 1). These goals and objectives are measured through teacher observation. Self-recording is not used as a method of evaluation in the creative curriculum. It is entirely completed through teacher observation. 
As a by-product, the child's initiation to work on skills was also examined throughout this project. During the initial phase of the study, an initiation chart was developed by the researcher and observer (see Table 1). Initiation was defined as the child asking to work on their individual project. Naturalistic observations taken during regular classroom activities were used to determine the amount of initiation used by the child prior to intervention phases. The researcher worked with the child on each of the designed steps with the observer present for $70 \%$ of the steps. A chart (Appendix C) was used to indicate if the child accomplished the step. Inter observer agreement was determined by comparing the observations of the charts that the researcher and observer marked for the steps that both had observed. The researcher and observer compared outcomes to see if an agreement was determined. An overall point-by-point ratio of .92, with a range of .87 to 1.00 , was reached well exceeding the .80 goal to be considered reliable. The kappa coefficient, which adjusted for chance agreements, came to an average total of .91 with a range of .85 to 1.00 , again surpassing the .80 benchmark needed to be considered reliable. Agreement for both point by point agreement and kappa was calculated at such a high rate due to the researcher and observer's familiarity with the participants and the facility. Also, organized checklists were completed after observation of deciding on an appropriate goal, selfrecording, step by step instruction, and goal presentations.

\section{Procedure}

The pilot study and experiment 1 began in January of 2009 and continued until May 2009. The researcher and observer met with the children of the four and five year old class of the West Virginia University Nursery School in a group meeting to introduce the children to the idea of determining their own goals. With young children it was decided that giving possible examples of a goal would be the most appropriate way to explain the project. Children were 
encouraged to think of their own goal but using one of the examples was fine. All 20 children wanted to participate in the study throughout the academic semester. Their eagerness to participate was displayed in their behavior and the constant asking “Can I do it now?” Data were collected on all the children in regards to determining an achievable goal and their use of selfrecording.

Experiment 1 continued during the second phase of the study and began in September of 2009 and continued through the first week in December 2009. At this stage of the year, the children were younger and had one semester less of Nursery School experience than those in the pilot study. The researcher met with all children during a meeting time at Nursery School but chose the oldest children to begin the project and as others became interested they were added to the list of participators. A prior initiation chart was completed with each child to see if they initiated any activities prior to the project. The initiation chart was also completed at the end of each semester to see if there was a difference between the beginning of the semester, before the project began, and at the end of the semester, once the project was completed (see Appendix A). Data carried over from the pilot study to experiment 1, on the two returning children who constituted the case study and was collected until December of 2009. In each phase, participating children were brought to the office for their individual meeting with the researcher and observer to see if they could determine an appropriate goal. During this individual meeting, the child was asked what they wanted to learn when they worked individually with the researcher. If the child stated an inappropriate goal, the researcher and observer negotiated with the child to determine an achievable goal. The researcher and observer worked in the classroom with the child during the previous semester so both knew the capabilities of the child. Once the goal was set, the child, researcher, and observer signed a contract (Appendix B) which included the date and name of the 
achievable goal to be learned. The researcher and observer also completed a form, which included the child's name, date, and a section for whether the child sets an appropriate goal, does not set an appropriate goal, or if the child and researcher negotiates an appropriate goal. If the child stated a non-achievable goal the researcher, observer, and child negotiated an appropriate goal (see Table 1). Parents received a note card explaining the achievable goal the child, researcher, and observer agreed upon. In conjunction with the teacher who was also the observer, the researcher developed the incremental steps involved for each child's goal. Children often initiated when they wanted to work on their project with the researcher. Sometimes the researcher initiated the step by step instruction. It was noted on the data summary sheet (Appendix D), whether the child or researcher initiated the instruction. Each child had their own folder that was kept in the classroom for easy access.

Once the child and researcher decided to work on their project together, the child found their individual folder with their name located on the top. This folder contained the child's selfrecording chart of progress and the original contract signed by child, researcher, and observer. The self-recording chart was used after each incremental step of the goal was completed during individual instruction. The child self-recorded their own progress on this chart (Appendix C). At the top of the self -recording chart was a picture of the Mountaineer and once the child completed a step, they recorded their progress and became closer to the Mountaineer. Examples of children's self-recording included drawings such as flowers and smiley faces or indicators that were directly related to the skill such as letters and numbers. The researcher added the date and a brief description of what was accomplished during the individual instruction. On another form, the researcher added anecdotal information. The researcher reviewed the goal chosen by the child and began helping the child with the most basic step of that goal. Most goals were broken 
into seven observable steps, depending on the chosen achievable goal. A bulletin board located in the classroom, kept up-to-date information on the skills and goals completed by the children. Each time a skill was completed, a brief synopsis of the step was added to the board by the researcher so children and parents could review the progress. Throughout the step by step process, parents also received note cards that showed various pictures of their children and gave a brief explanation of their progress. Children kept track of their daily progress through observations of the bulletin board.

An example of learning to print the numbers 0-9 in incremental steps needed is as follows:

Step 1) During the first meeting the researcher wrote the numbers 0-9 down on a note card for the child to see. The number 0 was reviewed and discussed. The number was recited continuously between researcher and observer until the child can consistently repeat the number when asked. The child self- recorded the progress on the self -recording chart.

Step 2) The child or teacher initiated the next meeting and recited the number 0 to the researcher. The researcher in return discussed the next two numbers. The child repeated and then added the number zero before one and two. Child recited, “ $0,1,2$. . The child then self recorded their progress.

Step 3) The child or researcher initiated the third meeting and recited the numbers learned to this point, "0,1,2.” The researcher then added the next two numbers. Then the child repeated all five numbers learned and self -recorded his/her progress and moves to the next step.

Step 4) The child or researcher initiated the next meeting and recited the first five 
numbers “0,1,2,3,4.” One more number was added during this meeting. Child recited all six digits several times for the researcher. Child self -recorded progress and moved to the next step.

Step 5) The child or researcher initiated the next meeting and recited all six previously learned numbers " $0,1,2,3,4,5$ ” to the researcher. The researcher then added two more numbers. The child repeated the last two added "6,7" and then placed all eight numbers together in sequence and repeats. Child self -recorded progress and moved to the next step.

Step 6) Child or researcher initiated meeting and recited all previously learned numbers in order. The researcher added the final two numbers “8,9,”and child repeated them all together. The child was now able to recite numbers 0-9. The child self recorded progress and moved to the final step.

Step 7) The child or researcher initiated the final step, which was reviewing the previously learned numbers $0-9$. The child self -recorded the final step on the self- recording chart.

Once all observable steps were completed and the child achieved the established goal, the child had the opportunity to present his/her accomplishment to all the other children. The presentation included the researcher, observer, student-teachers, and all peers. During the presentation the child was introduced and asked to state the goal they worked on with the researcher. Children discussed what they learned with questions prompted by the researcher and observer. Peers also had the opportunity to ask the child questions regarding their project. In the example above, the child recited his numbers to peers. Once the presentation was completed, the child received a certificate of accomplishment indicating their goal was achieved. Upon 
completing a goal, children had the opportunity to continue with another individual goal. Throughout the intervention process a checklist was used to assure the proper procedures were followed throughout the study. The observer and researcher followed the checklist with each child.

In experiment 2 of this study, three additional children were used after the initial research was conducted. The researcher and the observer chose a common goal for the children to work on. This goal was to learn to write their last names. During baseline, anecdotal notes were charted on a form to see if children could print their last name. Children were asked to print their last name. The researcher observed the children's attempts to print their last name. Some children could identify their last name, identify the letters in their last name, hold a pencil correctly, but none were able to print their last name. Once baseline was stable for each of the three children, self-recording and individualized step by step instruction was introduced similar to the earlier part of the study and the steps were carried out as indicated previously. 


\section{Chapter III}

\section{Results}

\section{Pilot Study}

While working with the 20 children during the first phase of the study, one of the target behaviors was to see if a child could state an appropriate goal, or if it needed to be negotiated among the researcher, observer, and child. Out of 20 children participating in the initial part of the study, 11 appropriately stated an achievable goal while nine did not state an appropriate goal. A few examples of appropriately goals stated include, writing numbers $0-10$, writing their own play, reading a book, and putting puzzles together. A few examples of an inappropriately stated goal include, reading a book before the child is able to recognize letters and wanting to play hockey. One of the children who were able to state an appropriate goal had to have his goal narrowed; therefore it was further negotiated to become a more achievable goal. In essence, 55\% stated an appropriate goal and 45\% did not. These children negotiated and refined their goal with the researcher and observer. 
Table 1

Goal Negotiation Tally Sheet

\begin{tabular}{|c|c|c|c|c|}
\hline $\begin{array}{c}\text { Child } \\
\text { (Pseudonym) }\end{array}$ & Date & $\begin{array}{c}\text { States An Appropriate } \\
\text { Goal }\end{array}$ & $\begin{array}{c}\text { Does Not State An } \\
\text { Appropriate Goal }\end{array}$ & Negotiates Goal \\
\hline Amanda & 2/11/09 & $\mathrm{X}$ & & \\
\hline Amy & 2/9/09 & & $\mathrm{X}$ & $\mathrm{X}$ \\
\hline Catherine & $2 / 4 / 09$ & $X$ & & \\
\hline Christopher & 2/3/09 & & $\mathrm{X}$ & $\mathrm{X}$ \\
\hline Cindy & $2 / 3 / 09$ & $\mathrm{X}$ & & \\
\hline Cameron & $2 / 4 / 09$ & $\mathrm{X}$ & & \\
\hline Diana & $2 / 4 / 09$ & & $\mathrm{X}$ & $\mathrm{X}$ \\
\hline David & $2 / 2 / 09$ & $\mathrm{X}$ & & \\
\hline Eugene & $2 / 4 / 09$ & $\mathrm{X}$ & & \\
\hline Gwen & $2 / 5 / 09$ & & $\mathrm{X}$ & $\mathrm{X}$ \\
\hline George & 2/16/09 & & $\mathrm{X}$ & $\mathrm{X}$ \\
\hline Hannah & 2/3/09 & $X$ & & \\
\hline Jamie & 2/3/09 & & $\mathrm{X}$ & $\mathrm{X}$ \\
\hline John & $2 / 3 / 09$ & & $\mathrm{X}$ & $\mathrm{X}$ \\
\hline Jennifer & $2 / 3 / 09$ & $\mathrm{X}$ & & \\
\hline Kimberly & 2/3/09 & $\mathrm{X}$ & & \\
\hline Kurt & $2 / 3 / 09$ & & $\mathrm{X}$ & $\mathrm{X}$ \\
\hline Marshall & $2 / 3 / 09$ & & $\mathrm{X}$ & $\mathrm{X}$ \\
\hline Monica & $2 / 3 / 09$ & $\mathrm{X}$ & & \\
\hline Patrick & 2/3/09 & $\mathrm{X}$ & & $X$ \\
\hline
\end{tabular}

\section{Discussion}

There were several findings from this study. From the initial phase it was found that most of the children could establish an achievable goal. The majority (55\%) of children at the Nursery School stated an achievable goal. These children who were able to state an achieveable goal ranged in age between 54 and 67 months of age. This finding coincided with other researchers (Epstein, 2003; Hohmann \& Weikart, 1995) who believe that children can plan with intention. It can be speculated that because most of the children stated an achievable goal on the first try and the other children negotiated the inappropriate goal to an appropriate one, their goal 
making abilities would increase as they practiced. However, we cannot state this with certainty but would be a goal for future research. 


\section{Chapter IV}

\section{Results}

\section{Experiment 1}

\section{Case Study 1: David}

David is a 61-month-old, typically developing child who is currently attending the afternoon class at the WVU Nursery School. He is in his third year at Nursery School; therefore he is familiar with the staff, routine and environment. His twin brother, Patrick, also attends and is part of the current study. David and Patrick began the program at the age of three. It was noted by the teacher that David was very dependent on his brother and was by his side most of the day. Both boys moved into the afternoon class in fall 2008 and David became somewhat less dependent on his brother. However, once Patrick would leave a play area in the school, David would follow.

In January 2009, this study entitled, the Roy Moxley Project, after a former professor at West Virginia University, was introduced to all children. David, like the other children, was unsure of what the project entailed. After meeting with him one on one, David named goals he would like to work on at nursery school. He initially said that he wanted to learn how to play soccer and football, but was told that this was something he could work on later with the teacher. Next he said, “I don’t know what I want to do then.” The researcher and observer then negotiated with David a few options that may be a good start for him. The suggested goals included, working on his lowercase letters, learning his phone number, and writing a story. David wanted to learn to write and recite his phone number. He along with the researcher and observer signed and dated the contract stating that he was going to learn his phone number. A note card was then given to David's parents stating the goal he wanted to achieve, along with a 
picture of him signing his contract. The following table shows the individualized steps completed to achieve his first individual goal (see Appendix C for the full chart).

Table 2

Goal 1 - Steps self-recorded to learn to recite and write phone number (pseudo number)

\begin{tabular}{lc}
\hline \multicolumn{1}{c}{ Skills/Behaviors } & Dates \\
\hline $\begin{array}{l}\text { Described what a phone number is and learned the number 3 by repeating it } \\
\text { aloud. Wrote the number 3. }\end{array}$ & $2 / 5 / 2009$ \\
$\begin{array}{l}\text { Reviewed the previously learned number 3 and added 0-4. Repeated 3-0-4. } \\
\text { Wrote the number 3-0-4. }\end{array}$ & $2 / 9 / 2009$ \\
$\begin{array}{l}\text { Reviewed numbers 3-0-4 and learned numbers 5 \& 9. Repeated 3-0-4-5-9. } \\
\text { Wrote the numbers 3-0-4-5-9-4. }\end{array}$ & $2 / 12 / 2009$ \\
$\begin{array}{l}\text { Reviewed numbers 3-0-4-5-9 and added 4. Repeated 3-0-4-5-9-4. Wrote the } \\
\text { numbers 3-0-4-5-9-4. }\end{array}$ & $2 / 23 / 2009$ \\
$\begin{array}{l}\text { Reviewed numbers 3-0-4-5-9-4 and added 5 \& 5. Repeated 3-0-4-5-9-4-5-5. } \\
\text { Wrote the numbers 3-0-4-5-9-4-5-5. }\end{array}$ & $2 / 24 / 2009$ \\
$\begin{array}{l}\text { Reviewed numbers 3-0-4-5-9-4-5-5 and added 5 \& 5. Repeated 3-0-4-5-9-4- } \\
\text { Reviewed his phone number and practiced writing all the numbers for his } \\
\text { presentation. }\end{array}$ & $2 / 26 / 2009$ \\
Presentation of first individual goal & $3 / 3 / 2009$ \\
\hline
\end{tabular}

When self-recording his first individual goal, he used a smiley face to keep track of his own progress. The smiley face consisted of two eyes, a nose, and a mouth. The researcher initially told him "Once you completed your first step, make a mark of some kind to know that you have completed this step and can move closer to the "mountaineer." A picture of the WVU Mountaineer was placed at the top of the self-recording page. He continued to self-record a similar smiley face throughout all seven observable steps. When he was able to write and recite his full phone number he self-recorded his last step and sang, "I got to the mountaineer, I got to the mountaineer!"

David was then able to present his achieved goal in front of his peers and teachers. During this time, all of his classmates and teachers gathered around and David sat on a chair in front of everyone. The researcher prompted his presentation by asking him to tell everyone what 
he learned. He replied, "My phone number.” Then without being asked to give his phone number, David began to say, “3-0-4-5-9-4-5-5-5-5. Then he wrote down each number in order on a clip board. When he finished writing, he turned it around and showed the class his numbers. He pointed to each number individually as he read them aloud. When he was finished, the class clapped for him and David was extremely proud of what he had accomplished. The researcher then handed him a certificate that read Certificate of Achievement - David has completed his first individual goal of reciting and writing his phone number on 3/5/09 (see Appendix E). Before returning to circle time, David asked, “Can I put this certificate in my locker so I can take it home?” David was the first child to plan, complete all seven observable steps, self-record, and present his goal. After his presentation, several other children said, "When do I get to present? Can I go next? What is my goal going to be?”

On March 11 of 2009, David initiated to the researcher that he wanted to, "do another goal.” The researcher, observer, and David met in the office and discussed some new achievable goals for him. David said that he wanted to read a book. Although David knew his letters, the researcher and observer had to negotiate with David to find a book that would be appropriate for him to begin reading. It was negotiated that David would begin reading a predictable readers book for his next goal. Several books were laid out for David to choose from and once chosen, a new contract was signed and dated between the researcher, observer, and David. It was also noted that he wanted to read a predictable reader's book called The Party. When David signed the top of his second self- recording chart, he counted the number of boxes on the chart and said, "I only need seven more until I get to the mountaineer and I get to present my book!” A note card was given to his parents stating that his second individual goal was to read the book The 
Party. The following table shows the individualized steps completed to achieve his second individual goal (see Appendix C for the full chart).

Table 3

Goal 2 - Steps self-recorded to learn to read the predictable reader book The Party.

\begin{tabular}{lc}
\hline \multicolumn{1}{c}{ Skills/Behaviors } & Dates \\
\hline $\begin{array}{l}\text { Read the title, the author, the illustrator, and pages 1-2. Discussed what the } \\
\text { author does compared to the illustrator }\end{array}$ & $3 / 24 / 09$ \\
Read the title, reviewed the author and illustrator, and pages 1-4. & $3 / 31 / 09$ \\
Read the title, reviewed the author and illustrator, and pages 1-6. & $4 / 2 / 09$ \\
Read title, reviewed the author and illustrator, and pages 1-7. & $4 / 6 / 09$ \\
Illustrated an alternate ending to the book The Party. & $4 / 7 / 09$ \\
& $4 / 9 / 09$ \\
Read entire book and added last page. & $4 / 13 / 09$ \\
Practiced reading the entire book to his friend and took book home to read to & $4 / 15 / 09$ \\
his parents. &
\end{tabular}

On April $6^{\text {th }}$ David was playing Candy Land with his brother and a few friends in the block area. He along with the other children was asked to clean up and go to their circle times. David began to cry for his mother as other children went to circle time. The researcher took David to the side and talked to him about seeing his mother after circle and center time was finished. As he continued to cry and scream, circle time ended and children were walking to choice activities prepared by student teachers. The researcher asked David if he would like to work on his project. Suddenly David stopped crying and said, "Yeah! I want to work on my project. Maybe I can do another step before Patrick does.”

Once he read his book, he said he wanted to add another page at the end. The researcher asked why he wanted to add another page and he replied, "Because after the party you have to clean up.” He created a page to add to the end of the book that says, “The cleanup” and he illustrated himself in the story cleaning up the party. While illustrating his last page, his brother 
Patrick came by the table where we were working and asked David if he could help him color the clean up page. David replied yes and they both drew confetti with a red marker all over the page.

David once again had similar self- recording for each step completed. He drew a smiley face for each step, but unlike the first goal, his smiley face consisted of a circle around the face. For his first step he drew two smiley faces then continued with just one until he was able to reach the mountaineer, then he colored in the picture of the mountaineer. He said, "I'll scribble this part because it means I'm done with my goal.”

David presented on April 15th in front of his classmates and teachers. He sat in a chair as everyone else was on the floor. The researcher asked David to tell everyone what his goal was. He said, “I read The Party and added a page." David then began to read and said each word in a humorous voice. Although he kept the children laughing, he also was able to keep their attention throughout the story. The children enjoyed seeing David's page that he added at the end. When he finished, the researcher handed David a certificate that explained he had just completed his second individual goal (See Appendix E). The children and teachers all clapped for David as he smiled and took his certificate to his locker.

In May 2009, all children excluding David and Patrick graduated and would attend Kindergarten. Due to their young age, their parents requested they both return to Nursery School the afternoon class in the fall of 2009. On September 28 of 2009, all children were introduced to the new Nursery School located near a public park. In September, the study (the Roy Moxley Project) was introduced to a new group of children. David and his brother were able to help explain some examples of goals that children may choose to do. David told the children that last 
year he learned his phone number then he proceeded to say, "See I know my phone number 3-04-5-9-4-5-5-5-5.”

On September 29 of 2009, David initiated to the researcher that he wanted to "work on another goal.” He was very excited because he knew exactly what he wanted to do. He met with the researcher and observer to choose an appropriate goal to pursue. The researcher asked him what he wanted his goal to be and he replied, "I want to make something out of clay.” The researcher asked what he would like to sculpt out of clay and he replied, “a building.” The researcher, observer, and David then signed a contract stating that he was going to "sculpt a building out of clay.” A note card was sent home with David's parents stating that his third individual goal was to sculpt a building out of clay.

While working on each step of the individualized instruction, Patrick decided to help David with his sculpting. He was very involved in helping his brother make the best building possible to present to his classmates. When David was sculpting his slide, the researcher and his brother Patrick went to the playground to investigate the Nursery School slide in order to get more information. His brother offered various ideas of making the slide stand up on its own but David decided to just lean the slide ladder against the building, "I want to lean it because they have to get out of the building someway because there are no doors.” David also decided that he didn’t want to put a roof on his building, “I don’t want to put a roof on this because when I present, I want everyone to see in it.” David then chose three different colors to paint his building (red, blue, and green). He allowed Patrick to paint two walls green, while he painted the rest of his project. The following table shows the individualized steps completed to achieve his third individual goal (see Appendix C for the full chart). 
Table 4

Goal 3 -Learn to sculpt a building out of clay

\begin{tabular}{ll}
\hline \multicolumn{1}{c}{ Skills/Behaviors } & Dates \\
\hline $\begin{array}{l}\text { Drew a map of what he wanted his building to look like, which included: a } \\
\text { square building, a ladder, a slide, and mud at the end of the slide. }\end{array}$ & $10 / 2 / 09$ \\
$\begin{array}{l}\text { Reviewed his map and began to sculpt the slide } \\
\text { Finished sculpting the slide and began to sculpt the ladder and mud for the end } \\
\text { of the slide }\end{array}$ & $10 / 6 / 09$ \\
Sculpted two walls for his building & $10 / 12 / 09$ \\
$\begin{array}{l}\text { Sculpted two more walls of his building. Then began to paint the outside } \\
\text { walls. }\end{array}$ & $10 / 15 / 09$ \\
$\begin{array}{l}\text { With help from his brother, he painted the remainder of his project. (said he } \\
\text { didn't want to make a roof) }\end{array}$ & $10 / 19 / 09$ \\
Presentation of his third individual goal & $10 / 21 / 09$ \\
\hline
\end{tabular}

When self-recording it took David six steps to reach his goal thanks to the help from his twin brother Patrick. Although Patrick assisted David, David was the only one self-recording after each step completed. Unlike previous self-recordings where he only made smiley faces for his self-recordings, he changed his mark during completion of each step. He self- recorded the following markings: three smiley faces, a circle filled with dots, a blue circle, a circle around a check mark, and a circle around the number two. When he was able to reach the mountaineer he scribbled through the mountaineer image. The researcher asked "why did you scribble through the mountaineer on your sheet?” David responded by saying “It's because I'm finished with my building.

On October 22 of 2009, David presented his goal to the rest of the class. This was the first presentation in front of the new group of children and he knew he was the first to go. David told the researcher, "I have to go first so I can show the rest of them what to do, them never done this before." He stood proudly in front of the group of children who were confused on what was happening because they had not been a part of individual presentations before. David was shy when introducing his project to the class but with prompts from the researcher and observer. 
David was able to thoroughly discuss all aspects of his sculpture. He began by showing the original map he created then went on to describe the actual sculpture. He then went on to say the following during his presentation:

I made a building out of clay. This is the building that I made and painted. First I made the four walls then I made a slide so people can get out of the building. People can get in the building through going up the ladder. I made mud at the bottom of my slide because it's funny and if you go down you will get dirty.

Once he finished, children were able to ask him questions about his building. One child asked why he didn’t have a roof, windows or a door on his building. He replied, “Because I didn't want them.” The researcher then handed him a certificate that said he completed his third individual goal (see Appendix E). David then took his certificate to his locker as everyone clapped for him.

On October 28 of 2009, David fell outside on the playground and came into the office with a student teacher. He was crying and very upset with the scratch on his leg. Once David calmed down the researcher asked David if he wanted to work on a puzzle or read a book. David shook his head no. The researcher then asked David if he wanted to work on another project since he had completed his third goal. David shook his head yes. The researcher then asked David to get his folder and meet him at the table to sign his contract. The researcher and observer then sat with David and asked him what he wanted his next goal to be? He replied, "I want to learn to tie my shoes.” The researcher and observer both agreed that this would be an achievable goal for David. Once again the contract was signed and dated by the child, researcher and observer. A note card was sent home with David's parents stating that his fourth individual goal was to learn to tie his 
shoes. The following table shows the individualized steps completed to achieve his fourth individual goal (see Appendix C for the full chart).

Table 5

Goal 4 -Learn to tie his shoes

\begin{tabular}{|c|c|}
\hline Skills/Behaviors & Dates \\
\hline $\begin{array}{l}\text { Learned how to hold the strings of his shoes and make an X with them (cross } \\
\text { them). Then he looped it around and pulled through tightly. }\end{array}$ & $11 / 3 / 09$ \\
\hline $\begin{array}{l}\text { Practiced making the } \mathrm{X} \text { and pulling through then learned how to make a bunny } \\
\text { ear with one lace. }\end{array}$ & $11 / 4 / 09$ \\
\hline $\begin{array}{l}\text { Practiced making the } \mathrm{X} \text { and pulling through then learned how to make two } \\
\text { bunny ears. }\end{array}$ & $11 / 10 / 09$ \\
\hline $\begin{array}{l}\text { Practiced making the } \mathrm{X} \text { and pulling through then learned how to make two } \\
\text { bunny ears. }\end{array}$ & 11/17/09 \\
\hline $\begin{array}{l}\text { Used Patrick's shoe to practice making the cross (x) with his shoe strings then } \\
\text { made two bunny ears. }\end{array}$ & 11/30/09 \\
\hline $\begin{array}{l}\text { Practiced making the } \mathrm{X} \text { and pulling through then learned how to make two } \\
\text { bunny ears then pulled one through to tie his shoe. } \\
\text { Repeated two times. }\end{array}$ & $1 / 25 / 10$ \\
\hline $\begin{array}{l}\text { Practiced making the } \mathrm{X} \text { and pulling through then learned how to make two } \\
\text { bunny ears then pulled one through to tie his shoe. Repeated two times. }\end{array}$ & $1 / 27 / 10$ \\
\hline $\begin{array}{l}\text { Practiced making the } \mathrm{X} \text { and pulling through then learned how to make two } \\
\text { bunny ears then pulled one through to tie his shoe. Repeated two times. }\end{array}$ & $2 / 1 / 10$ \\
\hline Presentation & $2 / 1 / 10$ \\
\hline
\end{tabular}

This goal was much harder for David to complete than previous goals. He worked hard at achieving it but became frustrated when he wasn’t able to remember the steps in order. During several of the steps he had to repeat the steps to make sure he was able to remember it. This was a hard time to start his goal because the children were not at Nursery School most of December and January. However, he did a wonderful job working towards his goal and was able to use his brother Patrick for help when needed. When David didn't want to use his shoe to practice tying, his brother volunteered. David would use Patrick’s shoe for practice. Selfrecording by now seemed like second nature to David. After he would complete a step he would look for his self-recording sheet and a pencil and would automatically place a mark next to the 
step completed. His first self-recording was a smiley face and the rest of his recording were people with full bodies.

David was excited to give his presentation. He had waited a long time to learn to tie his shoes and was finally able to show his classmates and teachers what he was able to do. He took off his shoe and sat in a chair in front of the other children. He told the children that he learned to tie his shoes. One child replied, “I know how to tie my shoes already!” Several other children say, "I want to learn to tie my shoes for my project!" David then continued to go through all the steps in tying his shoes. When he finished he smiled and told the observer how hard it was to learn. He received his fourth certificate for completing his individual goal of tying his shoes (See Appendix E). He took his certificate to his locker to take home.

\section{Case Study 2: Patrick}

Patrick is a 61 month old, typically developing child who is currently attending the afternoon class at the WVU Nursery School. He is in his third year at Nursery School; therefore he was familiar with the staff, routine and environment. His twin brother, David, also attends and was part of the current study. Patrick and David began the program at the age of three. It was noted by the teacher that Patrick was more independent than his twin brother David, who heavily relied on his brother. Both boys moved into the afternoon class in fall 2009 and Patrick easily made friends while still playing and interacting regularly with his brother.

In January 2009, this study entitled, the Roy Moxley Project, after a former professor at West Virginia University, was introduced to all children. During the initial meeting when the study was first introduced, Patrick was the first child to raise his hand and say that he wanted to learn to play football. He appeared to be one of the only children to understand what the researcher and observer were referring to when they mentioned working towards a goal. 
While meeting with Patrick individually, the researcher and observer asked him what type of goal he would like to work towards while he was at Nursery School. Patrick instantly replied, "I would like to learn to write my favorite words with a marker.” The researcher and observer both agreed this was an appropriate goal for Patrick; however, he would have to narrow his goal to a certain amount of words. The researcher then asked Patrick if writing five words would be enough. The researcher, observer, and Patrick then all signed and dated a contract stating that Patrick was going to work towards writing his five favorite words using a marker (See Appendix C). A note card was then given to Patrick's parents stating the goal he wanted to achieve, along with a picture of him signing his contract. The following table shows the individualized steps completed to achieve his first individual goal (see Appendix C for the full chart).

Table 6

Goal 1 - Steps self-recorded to learn to write his five favorite words using a marker.

\begin{tabular}{lc}
\hline \multicolumn{1}{c}{ Skills/Behaviors } & Dates \\
\hline $\begin{array}{l}\text { Identified five favorite words to print (dog, car, ball, cat, and Ben). The } \\
\text { researcher wrote on sentence strips for later identification }\end{array}$ & $2 / 4 / 09$ \\
Practiced writing the letters D-O-G then wrote the word DOG three times. & $2 / 5 / 09$ \\
$\begin{array}{l}\text { Practiced writing the letters B-A-L-L then wrote the word BALL and Dog } \\
\text { three times. }\end{array}$ & $2 / 12 / 09$ \\
$\begin{array}{l}\text { Practiced writing DOG and BALL then practiced writing the letters C-A-R. } \\
\text { Wrote the word CAR. }\end{array}$ & $2 / 26 / 09$ \\
$\begin{array}{l}\text { Practiced writing the letters B-E-N then wrote the word BEN three times. } \\
\text { Reviewed the words DOG, BALL and CAR }\end{array}$ & $3 / 5 / 09$ \\
$\begin{array}{l}\text { Practice writing the letters C-A-T then wrote the word CAT three times. } \\
\text { Practiced writing all five words (dog, car, ball, cat, and ben) and is ready to } \\
\text { present. }\end{array}$ & $3 / 10 / 09$ \\
Presentation & $3 / 11 / 09$ \\
\hline
\end{tabular}

During the step by step instruction, the teachers initiated the first two meetings to begin his goal. Once he realized he was able to go to the researcher when he wanted to work on his project, he initiated the other five steps until completion. His first step consisted of choosing his 
five favorite words to write with a marker. He was very excited and started naming words that were appropriate for him to learn to write at the age of 54 months. Throughout each of the steps he learned to write one word and then each day before learning a new one, he reviewed by writing the previously learned words.

When self-recording his first individual goal, Patrick made two markings that resembled a backwards G and a C. He initially asked "Why do I write on here?” The researcher explained that this chart was to show that after each step is completed, we will mark it to show that we finished it. Then the researcher pointed at each step showing Patrick that once he completed all the steps and was able to reach the mountaineer, he would be able to present to the class because that meant that he was able to achieve his goal. Patrick said, “Ok” and completed his markings. During step two, Patrick self-recorded a circle, for step four he wrote the letter P and colored it in with a red marker. For step five and six he wrote the letter $\mathrm{P}$ and then for step seven he drew a line across his page and then colored in the mountaineer with a red marker.

Patrick presented to his peers on March 13 of 2009. He was very excited for his first presentation after seeing his brother present a week earlier. Patrick sat on a chair as his peers gathered around him. He had a clipboard and a marker given to him by the researcher. He introduced to the class what he was presenting, “I’m presenting words and writing them with a marker.” He began to write down each word carefully as the rest of the class observed. Once he finished he turned his clipboard around to show everyone his paper. The researcher asked him to point to each word and tell everyone what the word was. He replied, "Ben, cat, dog, car, ball.” Once he finished, he received a certificate from the researcher that read Certificate of Achievement - Patrick has completed his first individual goal of writing his five favorite words 
with a marker on 3/12/09 (see Appendix E). His peers then proceeded to applaud and Patrick took a bow.

Patrick was unable to begin another goal before school was out for summer. In May 2009, all children excluding Patrick and David graduated and would attend Kindergarten. Due to their young age, their parents requested they both return to Nursery School for the afternoon class in the fall of 2009. On September 28 of 2009, all children were introduced to the new Nursery School located near a public park. In September, the study (the Roy Moxley Project) was introduced to a new group of children. In a group meeting, Patrick and his brother were able to help explain some examples of goals that children may choose to do. Patrick told the other children that he "wrote words and it was fun."

After the group meeting was completed, Patrick asked the researcher "Can I work on my project now?” The researcher then grabbed Patrick’s folder and they both met the observer in the office. The researcher asked Patrick what he would like his goal to be for this project. Patrick replied, “I want to learn about football.” Both the researcher and observer believed this to be too broad and negotiated with Patrick to narrow his goal. Once negotiated, Patrick's goal was to learn about a football player's uniform. The researcher, observer, and Patrick then signed and dated the contract. A note card was sent home with Patrick’s parents stating that his second individual goal was to learn about a football player's uniform. The following table shows the individualized steps completed to achieve his second individual goal (see Appendix C for the full chart). 
Table 7

Goal 2 - Steps self-recorded to learn about a football player's uniform.

\begin{tabular}{lc}
\hline Skills/Behaviors & Dates \\
\hline $\begin{array}{l}\text { Printed out football player's uniform diagram. Learned about the football } \\
\text { helmet and football. }\end{array}$ & $10 / 2 / 09$ \\
$\begin{array}{l}\text { Discussed the parts of the helmet. Looked at a real helmet and labeled the } \\
\text { parts. Introduced the shoulder pads. }\end{array}$ & $10 / 6 / 09$ \\
$\begin{array}{l}\text { Reviewed the parts of the helmet and discussed the parts of the shoulder pads. } \\
\text { Introduced the football cleats. }\end{array}$ & $10 / 12 / 09$ \\
$\begin{array}{l}\text { Reviewed the helmet and shoulder pads. Discussed the hip pads and football } \\
\text { cleats. Discussed use for each part. }\end{array}$ & $10 / 19 / 09$ \\
$\begin{array}{l}\text { Reviewed each part of the uniform previously learned. Discussed football } \\
\text { safety. }\end{array}$ & $10 / 21 / 09$ \\
$\begin{array}{l}\text { Reviewed equipment, uniform, and safety of each piece. Will present } \\
\text { tomorrow. }\end{array}$ & $10 / 22 / 09$ \\
Presentation & $10 / 23 / 09$ \\
\hline
\end{tabular}

During step by step instruction, the researcher initiated the first and third meetings while Patrick initiated the rest. He really enjoyed this project and learned very quickly. The researcher was able to bring football equipment for Patrick to learn about and then share with his classmates. Patrick self-recorded a circle with several dots in the middle of it during completion of steps one and two, drew a circle and scribbled inside of it for step three, he drew a stick figure for step four, during step five he wrote his brother's name, during step six he wrote the letter ' $R$ ' and then presented during step seven. This goal took less time to achieve because he spent more intensive time working on each step. Patrick presented his project on October 23, of 2009 in front of his classmates and teachers. He stood with the researcher as the children sat around him. Patrick told the children, "I learned about the football uniform and how it keeps them safe.” He then individually held up each item and talked about how it was used and why it keeps players safe.

This is a picture of all the uniform. This is the helmet and it protects your head. It has pads inside so it makes it tight on your head. The chinstrap makes it tight too 
and it protects your chin. That is the facemask and it helps protect your face. It's illegal to grab onto this part. This is the shoulder pads; they protect your shoulders and your chest. Those are the football cleats they have things on the bottom that dig the turf. They make you faster. These are gloves and they help you catch the ball. It feels like rubber on the bottom. This is a mountaineer jersey; you wear the jersey over the shoulder pads. Am I forgetting anything? Oh the hip pads they help protect your hips you wear those under your pants.

As Patrick finished his presentation and received his certificate indicating he had completed his second individual goal, all of the children and teachers applauded. Patrick bowed to his peers then hurriedly took his certificate to his locker. Before dismissing their large group circle, several children asked “When do I start my project?” and "What can I learn about?” They were advised that the researcher and observer would meet with each child individually so they could choose what they wanted to work on.

On October 29 of 2009, Patrick went to the researcher and asked, "When can I present again?” The researcher told Patrick to retrieve his folder and he would be able to choose another goal. Patrick then proceeded to the office with the researcher and observer to decide another goal. Patrick was unsure of what he wanted to do for this goal so the researcher gave a few examples such as, writing numbers and learning to read and/or write more words. As soon as the researcher and observer mentioned the word read, Patrick announced, "I want to read a book like David did.” The researcher and observer agreed that Patrick was ready to begin reading a predictable reader's book. Patrick was given several books to choose from. He chose to read a book entitled, The Park. The researcher, observer, and Patrick then signed and dated his 
contract. A note card was sent home with Patrick's parents stating that his third individual goal was to read The Park.

During step by step instruction, Patrick initiated each step with the researcher. After completing each step, he was very proud of himself because he was able to "read" he would tell the other children that he was reading a book and even took the book home with him once he finished reading it. He asked the researcher, "Can I take this home with me to read? I want to practice and show them my pictures.” Patrick was able to take his book home and returned it the next day. The following table shows the individualized steps completed to achieve his third individual goal (see Appendix C for the full chart).

Table 8

Goal 3 -Steps self-recorded to learn to read The Park

\begin{tabular}{lc}
\hline \multicolumn{1}{c}{ Skills/Behaviors } & Dates \\
\hline Read the title page to page 3. Reviewed the author and illustrator. & $11 / 2 / 09$ \\
Read the title, title page. To page 5, then reread the front page. & $11 / 3 / 09$ \\
Read the rest of the book twice & $11 / 4 / 09$ \\
Read the entire book two times & $11 / 10 / 09$ \\
Read the book through once then added two pages on to the end. & $11 / 12 / 09$ \\
Read entire book then illustrated pictures onto the added pages. & $11 / 17 / 09$ \\
Practiced reading entire book and added pages. Presenting book on 12/2 & $11 / 30 / 09$ \\
Presentation & $12 / 2 / 09$ \\
\hline
\end{tabular}

While self recording each individualized step, Patrick self recorded the letter 'R'.

Interestingly, he self recorded the letter ' $\mathrm{R}$ ' after each step was completed without being asked to self-record by the researcher. He alternated between lowercase and uppercase ' $\mathrm{R}$ ' and then circled the mountaineer once he achieved his goal. The researcher asked Patrick why he decided 
to write the letter ' $\mathrm{R}$ ' after each step and he replied, “Because I needed to work on writing that letter.”

On December 2 of 2009, Patrick presented his book in front of the class. He sat in a chair in front of his peers and told the children "I'm going to read a book.” One of the other children asked Patrick what his book was called and he replied, “The Park.” He read the title, title page, and then began to read the rest of the book one page at a time. He took his time reading and pronounced each word correctly. After reading the book, he read the pages that he dictated and illustrated to end the story. These additional pages read, We have a picnic. We go to the Park. We play with airplanes. We go to the Park. When he finished everyone applauded as he received his third certificate. He asked “Can I stick this in my locker?” Meanwhile, one child who does not participate often in classroom discussions or conversations asked the researcher and observer, "When can I present?” It was explained that she would be able to present soon, once she found a goal she would like to achieve and was able to work on it with the researcher. Once this was explained all of the other children said, "I want to present, I want to present, I want to present.”

On January 27 of 2010, Patrick approached the researcher and said “I’m ready for another project. When can I work on my next project?” As soon as Patrick mentioned starting a new project, the researcher retrieved his folder and took Patrick into the office to meet with the observer. Before being asked what goal he would like to achieve next, he enthusiastically told the researcher and observer, "I want to read another book!” The researcher and the observer agreed that this was an appropriate goal for Patrick to achieve since he did such a good job reading the first book. The researcher, observer, and Patrick then signed and dated his forth contract. Patrick once again had a group of predictable reader books to choose from. He chose 
to read the book entitled My Bus. A note card was sent home with Patrick's parents stating that his fourth individual goal was to read My Bus. The following table shows the individualized steps completed to achieve his fourth individual goal (see Appendix C for the full chart).

Table 9

Steps self-recorded to learn to read My Bus

\begin{tabular}{lc}
\hline \multicolumn{1}{c}{ Skills/Behaviors } & Dates \\
\hline Read the title, title page and learned about the author and illustrator & $1 / 28 / 10$ \\
Read the title, title page, and pages 1-2. & $2 / 1 / 10$ \\
Read the title, title page, and pages 1-5. & $2 / 10 / 10$ \\
Read the title, title page, and pages 1-7. & $2 / 11 / 10$ \\
Read title, title page, and pages 1-8. & $2 / 12 / 10$ \\
Read the entire book and added an additional page at the end. Dictated and & $2 / 5 / 10$ \\
illustrated the alternate ending to the researcher. & $2 / 16 / 10$ \\
Read the entire book including his added page. & $2 / 17 / 10$ \\
\hline
\end{tabular}

During step by step instruction, the researcher initiated the first step but Patrick initiated each step thereafter. His self-recordings were similar after each step but differed in complexity. After his first two steps were completed he drew a basic stick figure person. After step three was completed he drew two stick figure people. For step four he drew a box with two dots inside of it, for step five he drew waves and for step six he drew a more elaborate person. When he achieved his goal, he colored in the mountaineer. The researcher asked him why he colored in the mountaineer and he replied, “Because it means I’m ready to present.”

On February 17 of 2010, Patrick presented his fourth individual goal. He sat in front of the other children and read each page carefully. He would read a page and then show the audience the picture. Most children would say “I can’t see the picture!” Patrick would reply, I’ll 
show you in a minute.” Once he read through the book he showed everyone the page he created. The last page of the book said "My Bus” and Patrick's added page said "My School” and he drew a picture of the Nursery School. Once he finished he received his fourth certificate stating he had achieved his goal and everyone applauded. He then took his certificate to his locker.

\section{Data Analysis: Case Studies}

In this study, the first target behavior in the case study was to ask a child to state an achievable goal that he or she wanted to learn. The researcher recorded on the tally sheet if the child stated a goal that was achievable or if an achievable goal needed to be negotiated. During the first individual meeting, David was unable to state an appropriate goal to achieve. Therefore, the goal needed to be negotiated with the researcher, observer, and child. Patrick however, was able to state an appropriate goal, but was asked to narrow the topic to a specific area of football. During the second individual meeting David was able to name an appropriate goal. Patrick was also able to state an appropriate goal, but once again it was too broad and needed to be refined so the goal was negotiated with Patrick, the researcher, and observer. During the third and fourth individual meetings, both David and Patrick were able to state appropriate goals to achieve. Accomplished goals through self-recording for David were learning his phone number, reading a book called The Party, sculpting a building out of clay, and tying his shoes and for Patrick they were writing his five favorite words with a marker, learning about football player's uniform, reading a book called The Park, and reading another book called My Bus. Overall, out of the four goals each accomplished (eight total) there was only one occurrence when a goal was not appropriate. Two goals total were appropriate, but needed to be narrowed to a specific area with the researcher, observer, and child. 
Once an achievable goal was established and the researcher specified the steps of the goal, the second target behavior was to see if child could self-record their own progress. Selfrecording was introduced to David and Patrick once they completed their first step of the first goal. They were reminded second and third step about the self-recording. After this point, they automatically picked up their self-recording sheet and self-recorded after the researcher wrote the date and behavior/skill. Having the mountaineer image located at the top of the self-recording sheet enabled both David and Patrick to have a visual marking indicating completion of their work. The closer they were to the mountaineer, the more they initiated their goal so they would be able to present. The following charts show the steps completed following self-recording of progress.

Figure 1

The steps needed for David to achieve his first individual goal.

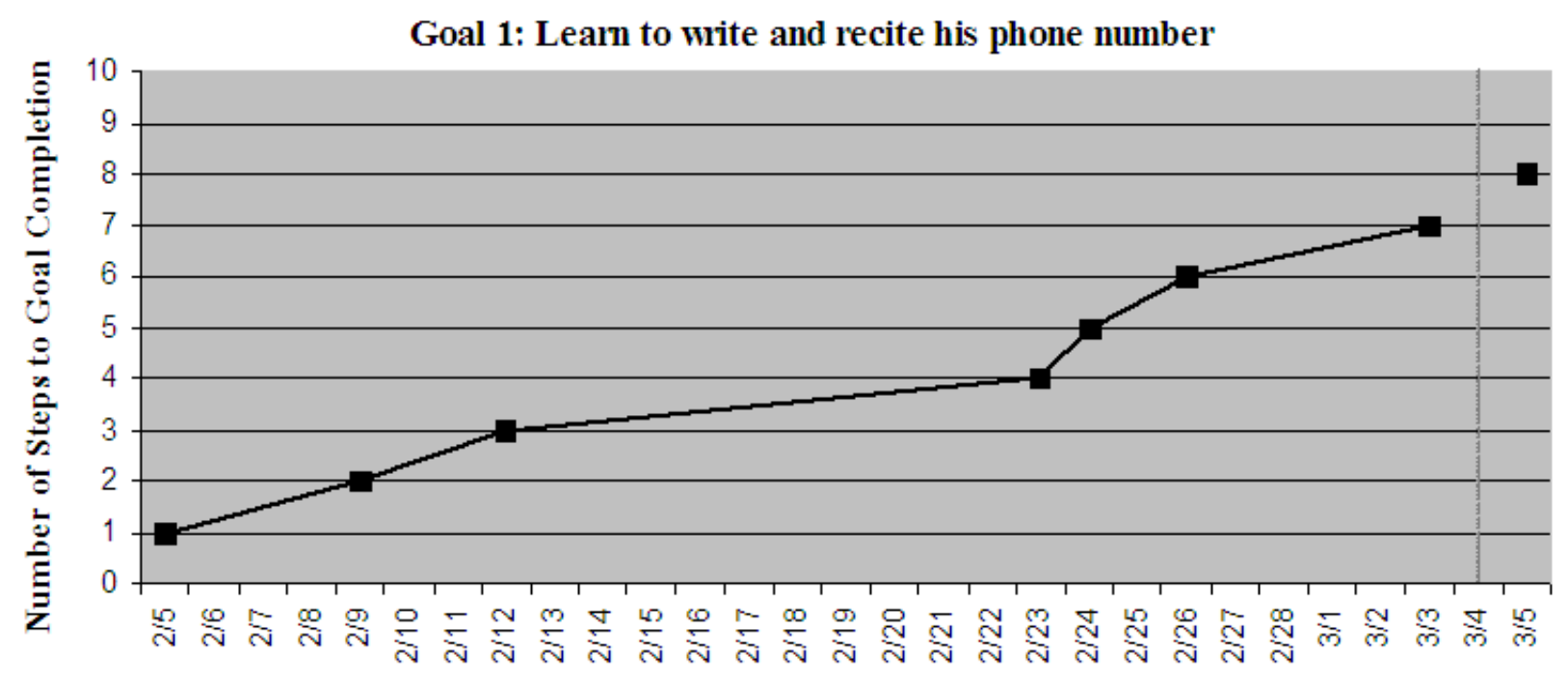

Dates/Sessions (2009) 
Figure 2

The steps needed for David to achieve his second individual goal

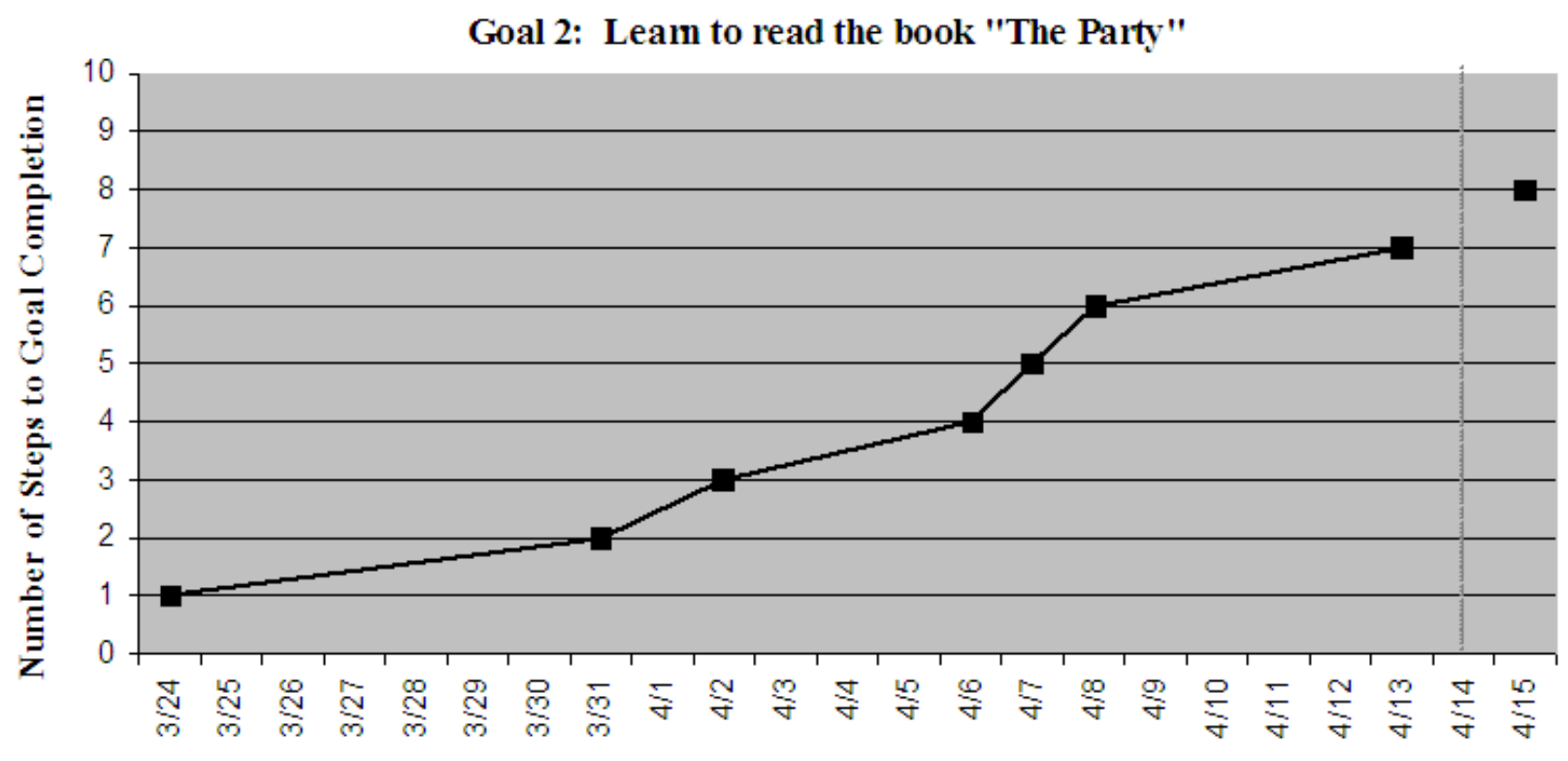

Dates/Sessions (2009)

Figure 3

The steps needed for David to achieve his third individual goal

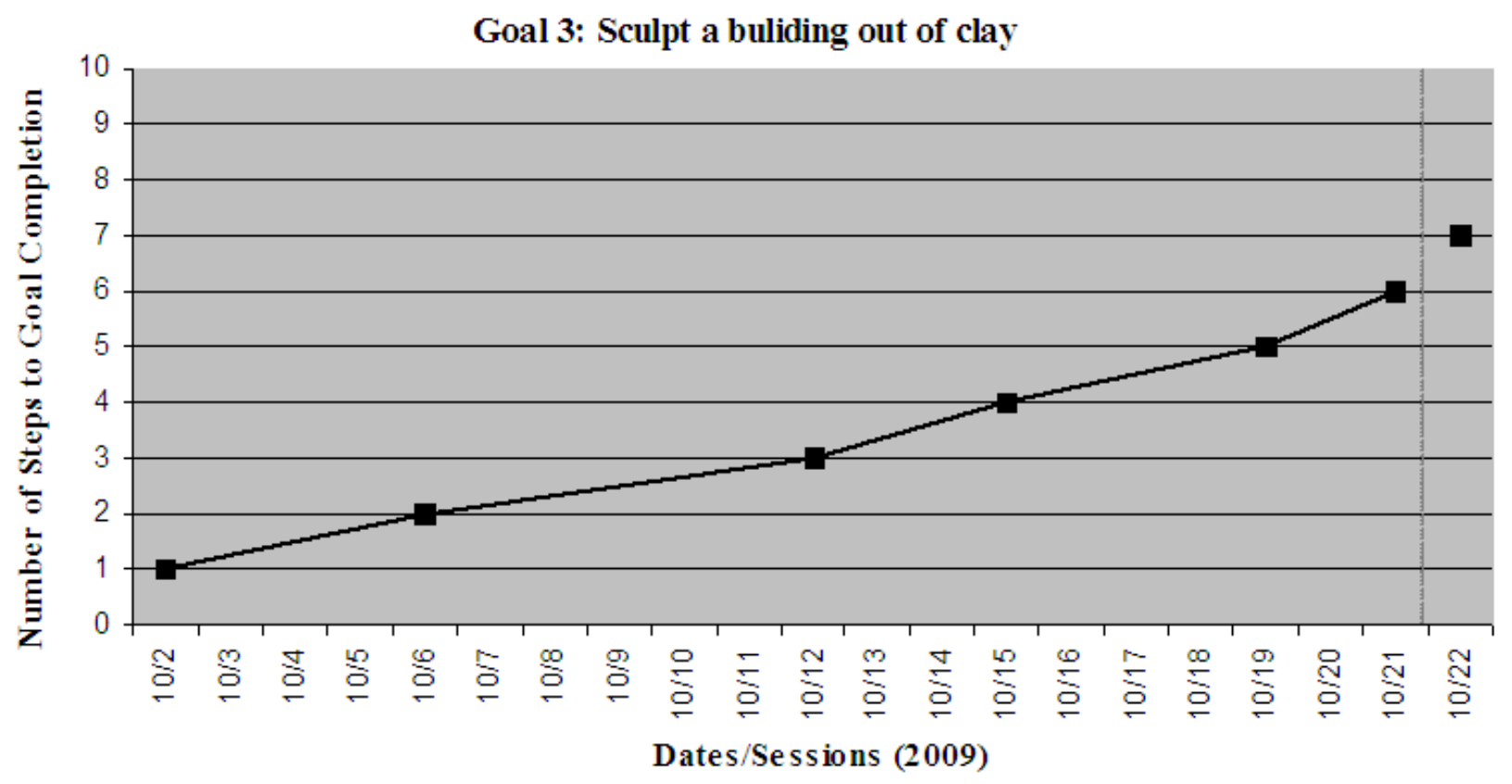


Figure 4

The steps needed for David to achieve his fourth individual goal

Goal 4: Learn to tie shoes

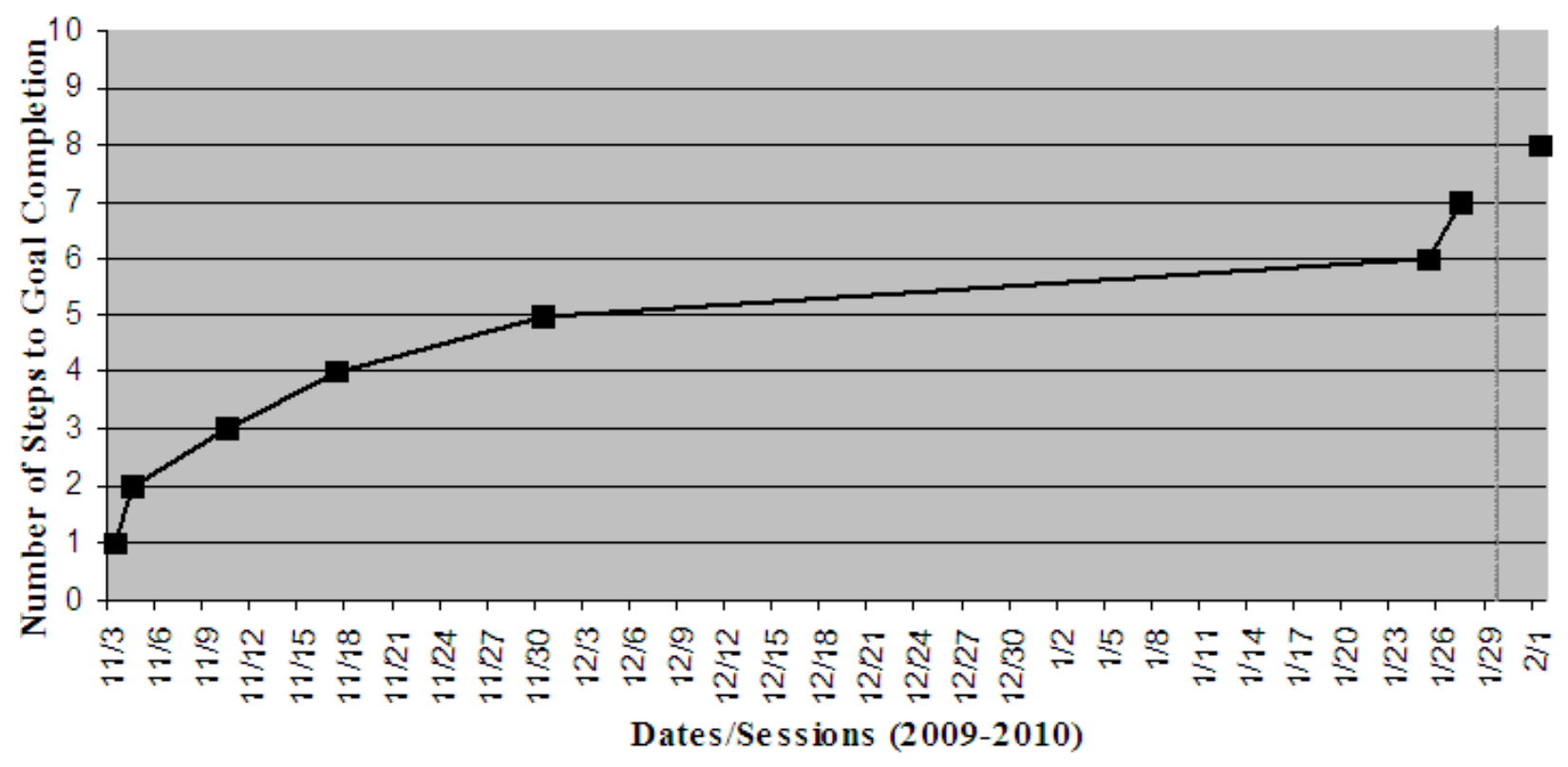

Figure 5

The steps needed for Patrick to achieve his first individual goal

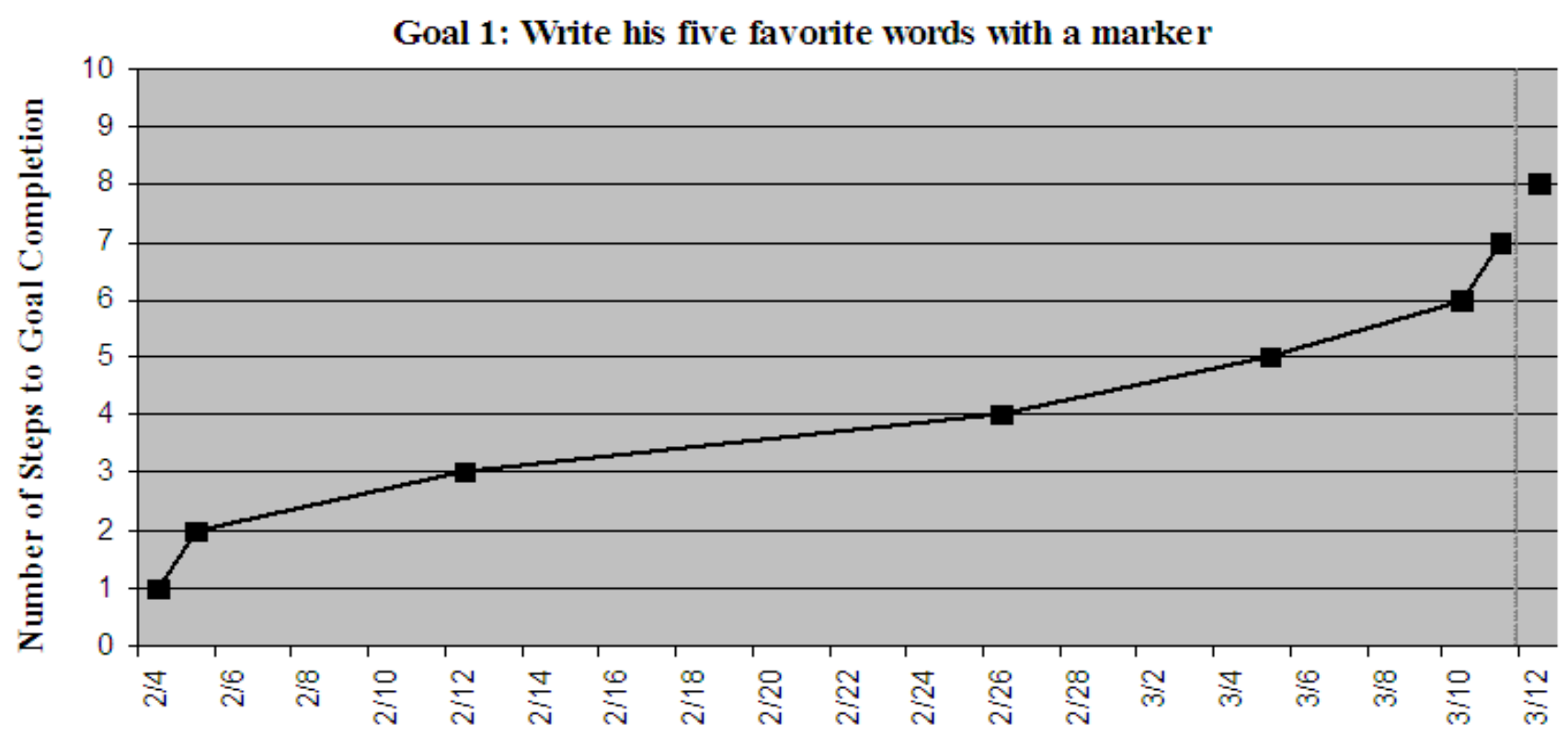

Dates/Sessions (2009) 
Figure 6

The steps needed for Patrick to achieve his second individual goal

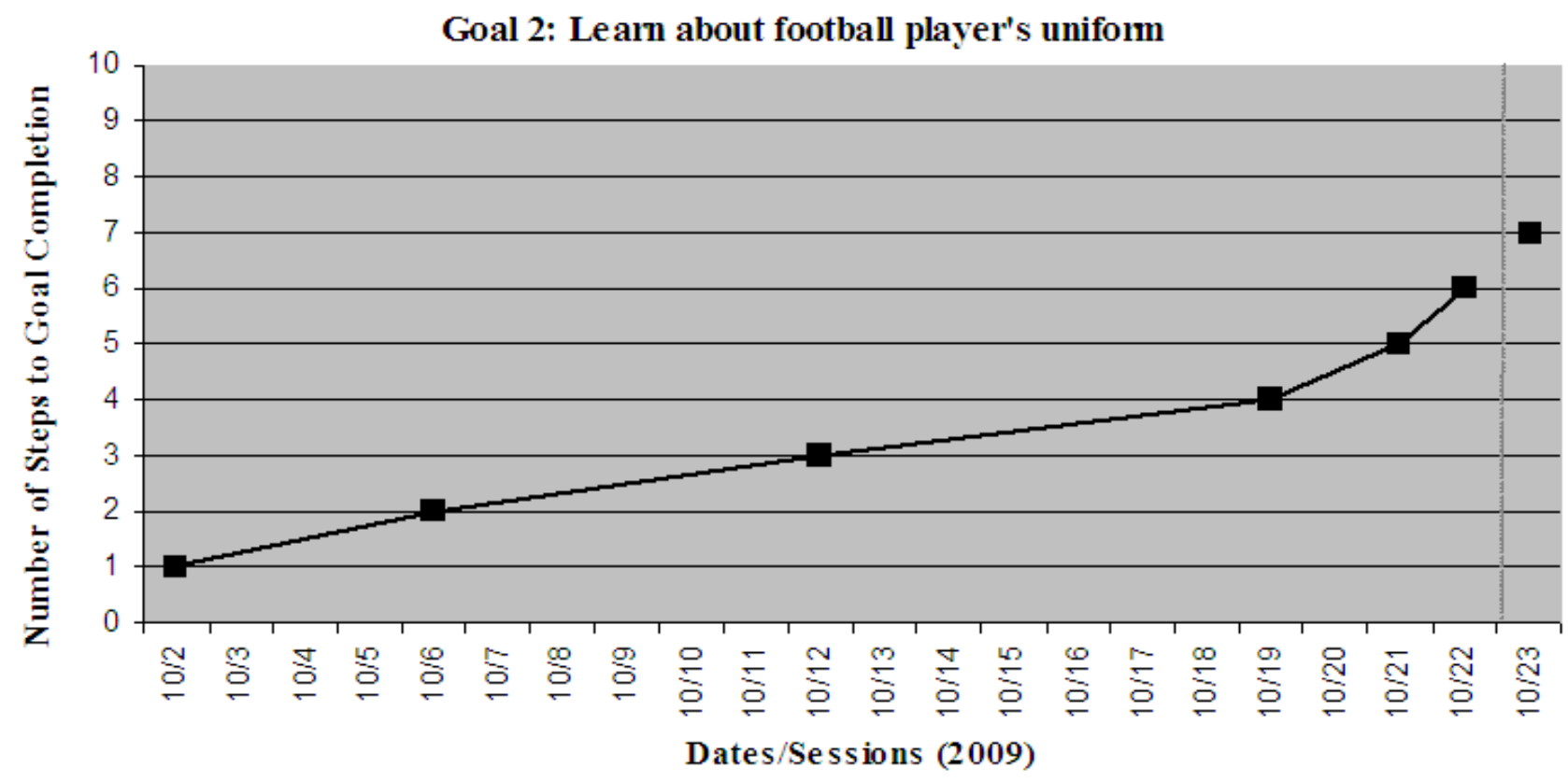

Figure 7

The steps needed for Patrick to achieve his third individual goal

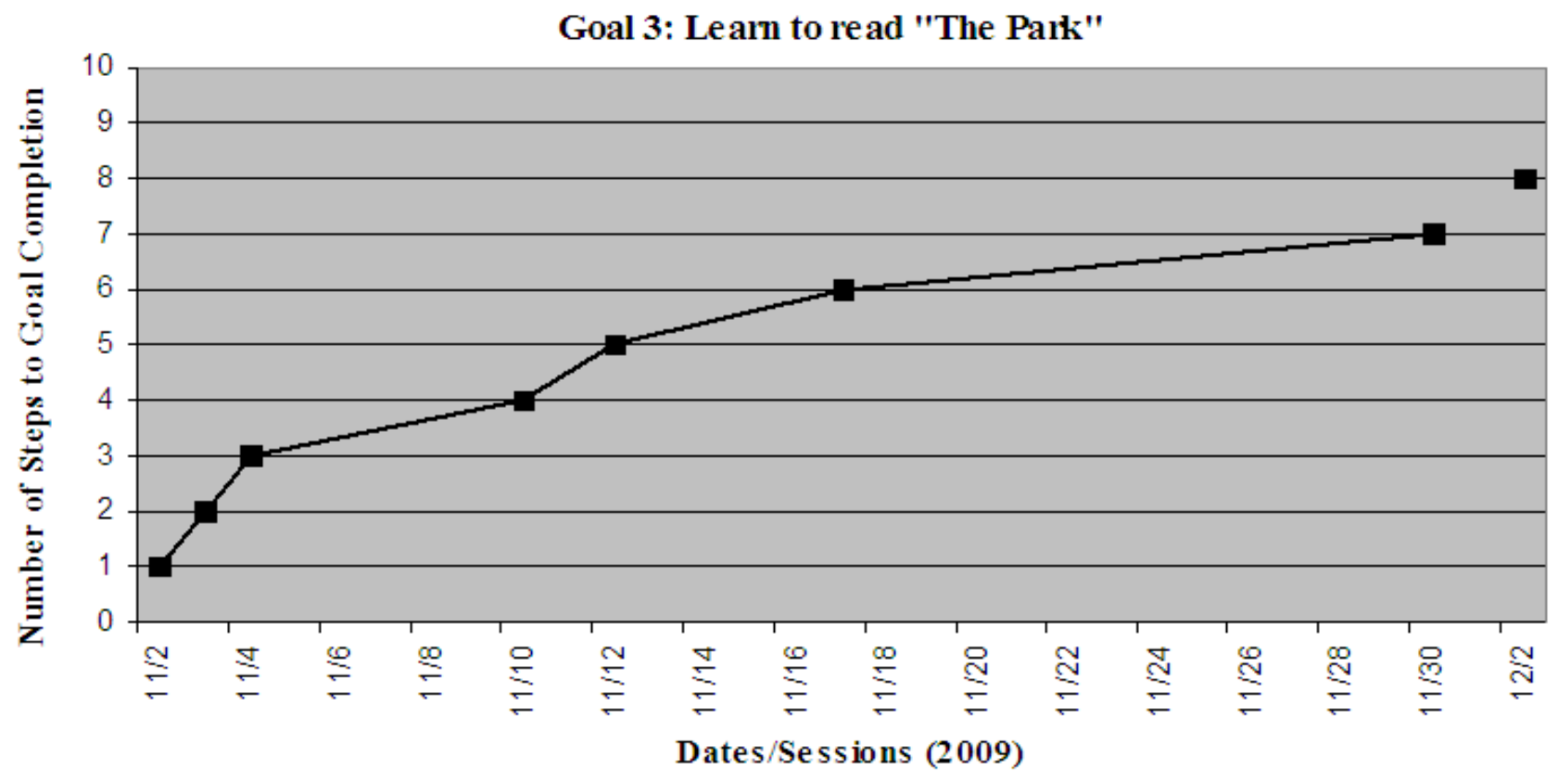


Figure 8

The steps needed for Patrick to achieve his fourth individual goal

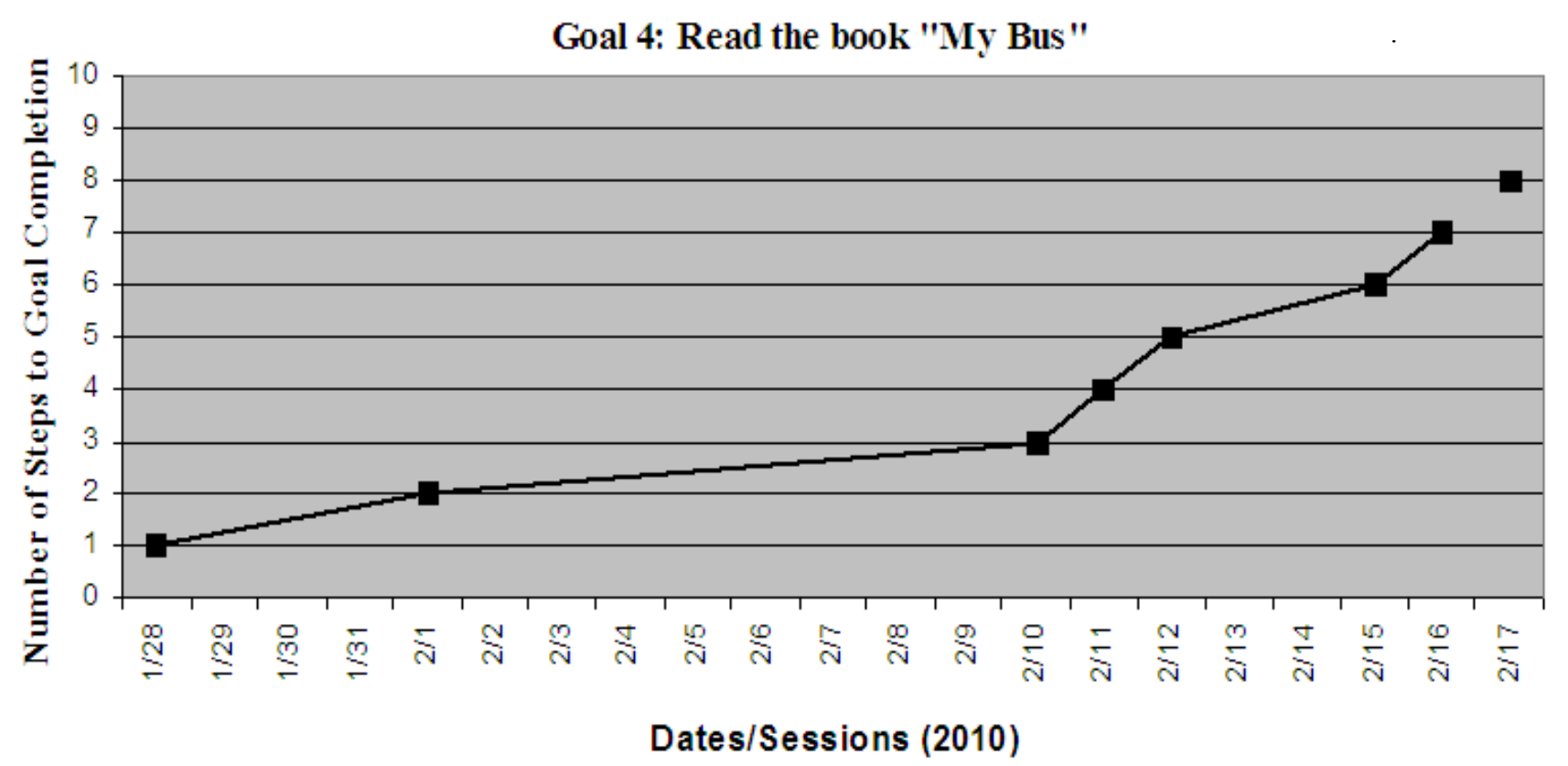

In each Figure (1-8), there was significant increase in data points from step one to the final step. The presentation given by each child once the goal was achieved was shown as a separate data point during the final date listed. The presentation represented the follow-up of the study along with other daily classroom activities. Weekends were represented on the chart as well as holiday breaks when the Nursery School was closed. There was no decrease in steps shown in Figures 1-8, after weekends and/or long breaks from school and no extra reviews were needed.

Child initiation was another aspect included in this study. It was noted if the researcher or the child initiated the project and/or the individual meeting for step by step instruction. The teacher initiated the first goal for both David and Patrick due to the novelty of the study. Once the first goal was established, David initiated the first, third, and fourth individual meeting, while the researcher initiated the second, fifth, sixth and seventh individual meeting. Patrick on the 
other hand initiated the third, fourth, fifth, sixth, and seventh meeting while the researcher only had to initiate the first and second meeting. Once their first goal was achieved, both David and Patrick initiated their second goals of the study. David initiated the second, third, fourth, fifth, and sixth meeting while the researcher initiated the first and seventh meeting. Patrick initiated the second, fourth, fifth, and sixth meeting while the researcher only initiated the first and third meeting. Once their second goals were achieved, both David and Patrick again initiated their third achievable goal. David initiated the first through fifth meeting and the researcher initiated the sixth meeting. Patrick initiated all seven meetings during his third individual goal. Once goal three was completed, again David and Patrick both initiated their fourth individual goal. David initiated the first through sixth meeting and the researcher initiated the seventh and eighth meeting. Patrick initiated meetings two through seven while the researcher initiated the first meeting. When examining the initiation throughout the study, both David and Park initiated at a consistent rate for each goal. In only one instance (the first goal), the researcher initiated the goal then thereafter both boys indicated to the researcher that they wanted to begin a new goal.

Presentations were given after each child was able to achieve their individual goals. Both David and Patrick were able to effectively give their speeches to their classmates through accurate descriptions and analysis of their achievable goals. Once they discussed their goals, children in the audience stayed engaged by asking questions pertaining to their presentations. This in return allowed other children to initiate their individual goals.

In regards to accuracy, checklists were completed during each step of the data collection process for both David and Patrick between the researcher and observer. Inter observer agreement was assessed through the point-by-point ratio and kappa coefficient. An overall pointby-point ratio of .92 , with a range of .87 to 1.00 , was reached well exceeding the .80 goal to be 
considered reliable. The kappa coefficient, which adjusted for chance agreements, came to an average total of .91 with a range of .85 to 1.00 , again surpassing the .80 benchmark, needed to be considered reliable. Agreement for both point by point agreement and kappa was easily calculated due to the researcher and observer's familiarity with the participants. Also, organized checklists were completed after observation of deciding on an appropriate goal, self-recording, step by step instruction, and goal presentations.

\section{Discussion}

Upon visual and statistical examination of the case study data presented, results of this study support the hypotheses that children can increase their academic performance through choosing an appropriate goal and self-recording. In this study, children who were given step by step instruction and self -recorded their own progress achieved their goals. These findings are similar to previous research studies (Moxley 1983, 1984, 1990) that young children who selfrecord their own progress improve on the targeted skills. In addition, children in the case study were able to establish or negotiate an achievable goal. In fact, once they completed their first goal, they initiated a subsequent goal. In this study, children who participated in determining their own goals achieved their goals. If they were still unable to choose an appropriate goal, the researcher and observer continued to negotiate until an appropriate goal was obtained and agreed upon. The fact that they were involved in the planning their goals appeared to be a motivator. Throughout this study it was witnessed by the observer and researcher that David took more of an interest in this project that other school related activities. It was also noted through daily observations of normal classroom activities he successfully completed activities during play before moving to a new activity. David became more independent and less reliant on his brother

for leadership and support. Although he still enjoyed playing with his brother at Nursery School, 
he was able to socialize with other children throughout different activities. Although, there could be many factors involved with his new independence, achieving a goal through step by step instruction and self-recording is very visual and models a strategy for learning. In turn, it provided David with a sense of accomplishment. Studies (Epstein, 2003; Moxley \& Studwell, 1984) have shown that children participating in their own projects inherit such skills as selfmanagement and more elaborative self-recording this was said to be attributed to children being able to visually see their goals which were noted as an intrinsic motivator.

It was also noted by the researcher and the observer that Patrick was more patient and focused in his work. Through daily observations of normal classroom activities, his teacher said that he successfully completed projects before moving to another activity and he initiated more of his own play. The researcher also noted his desire to communicate what he wanted to achieve within his daily projects. He continued to be involved with his brother but to a lesser degree. He helped his brother achieve a couple of his goals by helping him paint his clay project and allowed him to use his shoe when David was trying to learn to tie. He also listened to David as he practiced reading the book, The Party. The involvement with his brother was more of an assistance rather than his former role of directing his brother. David's ability to initiate and socialize with others was a big step. It is difficult to pinpoint the reason for this new behavior. It could be that Patrick being more independent of him freed him of his former role of being the protector and leader of the two and gave David more of an opportunity to spread his wings.

Not only did the researcher and observer notice changes in David and Patrick’s academic and social performance at school, their parents commented on the behavioral changes. Their parents displayed a great deal of interest in this project and the goals that David and Patrick chose. In fact, the mother expressed that David and Patrick wanted to work on a project when 
completing daily tasks at home. She found it interesting that David chose the goals that he did and said she would have thought that Patrick would have chosen David's goals and David would have chosen Patrick's goal. She along with the researcher and observer believe that this project has contributed to David's growth as an individual by helping him to become more independent. Whether David becoming more independent as a result of participating in this study is hard to say but what can be said is that David did accomplish all of his goals by self-recording his progress and he did present to the class his accomplishments. Prior to the study, David would not get up in front of the class and shied from large group activities where he presented.

Self-recording proved to be an important indicator of goal achievement and academic performance. When a child initiated working on a project by asking the researcher instead of the researcher asking the child, this behavior of initiating activities and ideas carried over to other actions in the classroom. It was as though their ideas were valued. This could be attributed to the individual attention a child receives when working on a goal, a goal that they helped to decide. Again, this stems back to other research that children can be involved in making decisions and planning (Hohmann \& Weikart, 1995). When children self-recorded their own progress, it was also noted that their amount of initiation towards working on their 'project' increased. Both boys wanted to work on their project as well as the three children using self- recording to learn to print their names. In this study, the two children in the case studies increased their academic performance by achieving their goals. This achievement seemed to contribute to other behaviors in the classroom such as children initiating their own play or activity. Step by step instruction was carefully planned by the researcher and was useful in both self-recording and goal achievement. 
An added outcome of this study that was a significant side effect was the "presentation". When children completed their goal, they presented it to the class and the other children had the opportunity to ask questions and to clap. Presentations to the class reinforced the goal and gave children motivation to continue with further instruction. Whittin (1997) noted that it is crucial that children have the opportunity to share their projects and data visually with their peers and discuss their individual interpretations of what they have accomplished. Children wanted to present and often this spurred the initiation of a project by other children. One child not in the study who presented had her family come in to watch her presentation. This aspect of the study was interesting to observe as the children who had completed a project often helped other children pick a goal to work on. 


\title{
Chapter V
}

\section{Results}

\section{Experiment 2}

\section{Multiple Baseline Design Study}

\author{
Baseline
}

A multiple baseline design across participants was completed on three children in obtaining the goal of printing their last name. Normally this goal is started in February of each year with all children. Baseline data was recorded on the first child for a total of seven days, on the second child for eleven days, and on the third child for a total of fourteen days. During baseline the teacher initiated individual meetings with each child. During this time the child was asked if they could identify their last names from several others listed on a sheet of paper. Next without using any prompts from the teacher, children were asked to write any letters they may know in their last name. The total number of letters was then recorded by both the researcher and observer. During this time no step by step instruction or self-recording occurred.

\section{Intervention}

After a baseline was established for each child the intervention was applied. Children were introduced to their own individual folders, signed a contract (Appendix B) stating they were going to learn to write their last name (as chosen by researcher), and reviewed the selfrecording sheet. The researcher and observer observed each step and children self-recorded after each step was completed. During the intervention phase, although children were learning their letters in their last name one step at a time, children still had the opportunity to write as many letters as they knew in their name. All three children presented their last names in front of their 
peers upon goal achievement and this was represented as the follow-up in the study. The number of letters the child was able to write of their last name during each step was then recorded. 
Figure 9

The number of letters that children wrote in their last name during baseline and treatment phases

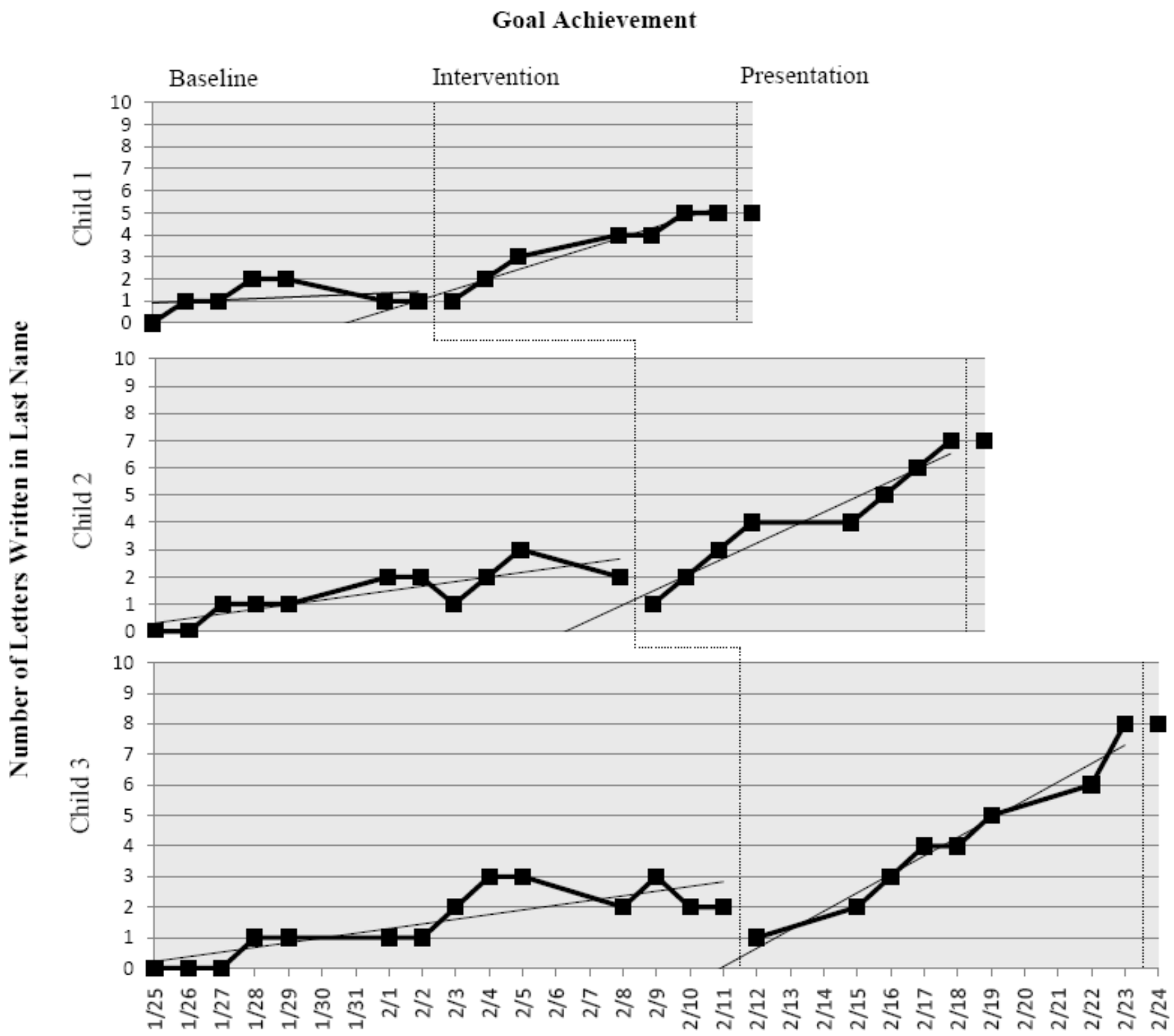

Dates/Sessions 


\section{Data Analysis: Multiple Baseline Design}

Data was visually examined and the mean, level, trend, and variability were calculated between each child and phase. The mean was measured by adding together all data points from the baseline and dividing them by the total number of letters written during baseline. The mean was then measured for treatment by adding together all data points and dividing them by the total numbers of letters written during the treatment phase. To determine change once the mean was established for both the baseline and the treatment, the baseline was subtracted from the treatment. For child 1, the calculated baseline mean increased from baseline $(+1.14)$ to treatment (+3.43). The change between baseline and treatment was an increase of +2.29 . Child 2 had a calculated baseline mean of +1.36 and a treatment mean of +4.00 . The change calculated between baseline and treatment was an increase of +2.64 , slightly higher than child 1 . Child 3 had a calculated baseline mean of +1.50 and a treatment mean of +4.13 . Once again the change from baseline to treatment was an increase of +2.63 , similar to child 2 . Once treatment was implemented for each child the change in mean increased steadily, this lead to the notion that once the step by step instruction and self-recording was implemented there was an increase in achievement.

When determining the level, the researcher looked at the final point of the baseline and compared it to the first point of the intervention. The treatment level was then subtracted from the baseline level to calculate change (See Figure 9). For child 1, there was no change in the final point at baseline $(+1.00)$ and the first point of the intervention $(+1.00)$. For child 2, there was a decrease in level from the baseline $(+2.00)$ to the treatment $(+1.00)$. When change was calculated, there was a decrease of level between baseline and treatment at -1.00 . Child 3 had a decrease in level between baseline $(+2.00)$ and the beginning of treatment $(+1.00)$. The change 
between baseline and treatment was a decrease of level at -1.00 . The slight decrease in the change in level can be attributed to the beginning of the treatment. Once the researcher intervened, the child started over with one letter (the first letter) of their last name and progressed upward with the correct letters in order.

The trend was determined by the increase, decrease, or steadiness of data for both the baseline and the treatment. Calculations were found by finding the slope of both the baseline and the treatment. The split middle technique was used to determine the slope by dividing data points into quarters and then each half of the data set into halves from low to high score. As can be viewed in Figure 9, child 1 had a slight upward trend (+.063) during baseline and then an increase $(+.46)$ during treatment. Child 1 had a change in slope of +.39 , as derived from the trend line from a regression analysis. Child 2 showed a slight upward trend (+.16) during baseline and an increase (+.56) during intervention. Child 2 had a change in slope of +.40 . Child 3 showed a slight upward trend (+.15) during baseline and an increase in trend $(+.60)$ during intervention. Child 3 showed a change in slope of +.45 . The increase in trend during the intervention phases across participants may be attributed to the total amount of letters in the child's last name. The first child only had five letters while the third and fourth child had eight. Also, achievement increased once the treatment was applied.

Variability will be calculated for baseline and treatment. Variability will be determined by analyzing the sudden increase and decrease of the data points and will be calculated through standard deviation (SD). Baseline for child 1 shows an increase of SD from baseline (+0.68) to treatment $(+1.50)$. The change in SD from baseline to treatment was at +0.89 , slightly higher than the baseline itself. Child 2's calculated SD slightly increased during baseline $(+0.91)$ to treatment $(+1.89)$. The change in SD from baseline and treatment was +0.96 . This once again 
was a slight increase from baseline. Finally child 3's calculated variability through SD showed another slight increase from baseline $(+1.09)$ to treatment $(+2.11)$. The change in SD from baseline to treatment was +1.02 . All three children had a slight increase in variability from baseline to treatment. Although the variability for each child was low, the variability may be attributed to the small amount of letters the children were able to write during baseline compared to the amount of letters learned in sequence throughout the intervention. During baseline most of the variability occurred after the weekends where for child 1 and child 3 there was a decrease or no change after weekend's occurred. The variability during treatment was low but did increase. After weekends occurred during treatment, there was an increase or no change for all three children.

Accuracy was once again calculated throughout experiment 2. Checklists were completed during each step of the data collection process for all three children between the researcher and observer. Inter observer agreement was assessed through the point-by-point ratio and kappa coefficient. An overall point-by-point ratio of .923, with a range of .91 to .94, was reached well exceeding the .80 goal to be considered reliable. The kappa coefficient, which adjusted for chance agreements, came to a total of .91 with a range of .90 to .93 , again surpassing the .80 benchmark, needed to be considered reliable. Agreement for both point by point agreement and kappa was easily calculated due to the researcher and observer's familiarity with the participants. Also, organized checklists were completed after baseline observations, selfrecording, step by step instruction, and goal presentations. 


\section{Discussion}

Upon visual and statistical examination of the data presented, the results of experiment 2 supported the findings from the case studies that self-recording increased academic achievement. Self-recording proved once again to be an important indicator of goal achievement and academic performance. These findings are similar to previous research studies (Moxley, 1983, 1984, 1990) that young children who self-record their own progress improve on the targeted skills. During experiment 2, using the multiple baseline across participants, the researcher and observer decided on a goal that would be the same for all children, therefore children did not choose their own goal. It was noted that the children did not initiate working on a goal as much when they did not chose the goal. Although printing their name was an important skill to be learned, it appears that determining one’s own goal is in itself a rewarding task. Children seem more motivated when they picked the skill. The more opportunities that children have in planning their work, the more focused they can become (Warash 1998, 2001, 2004; Lysyuk, 1998; Epstein, 2003; Hohmann \& Weikart, 1995).

Although children were not initiating as much, they were still self-recording and learning through step by step instruction, which increased their overall goal achievement. Placing an emphasis on the finished product was important in their goal achievement because presentations were highly sought after by all children. Studies (Moxley \& Studwell, 1984, Whittin, 1997) show that it is crucial that children have the opportunity to share their projects and data visually with their peers and discuss their individual interpretations of what they have accomplished to evaluate their progress. 


\section{Future Research}

Given the findings of experiment 1 and 2, future research may want to assess peer instruction and how it can affect learning outcomes. Throughout this study, children were interested in helping their peers achieve their goals especially in the case of the twins. Not only did they want to be involved in their own learning, but also each others. Peer instruction has shown to be a successful method in previous work (Warash, Curtis, Hursh \& Tucci, 2008). Peer modeling could be used to encourage children's participation in an activity. This would allow assistance needed for specific learners to successfully achieve their goals.

Social Interactions may also be examined in future studies to see how the study influences a change in social patterns from the beginning of the study to the final presentation and how this type of communication then carries over into the classroom. Over the course of the entire study, several children in the classroom observed during naturalistic observation were quiet and participated in solitary, onlooker, or parallel play. Once these children were able to choose and accomplish a goal, they appeared to have more confidence because they very much wanted to present in front of their classmates. This may also have implications for children’s development of self-esteem and self-efficacy.

\section{Limitations}

Although the original study was backed up by experiment 2, a baseline could have been used to calculate the change from the beginning when the twins initially started to achieve their goal without treatment. This would have given a clearer picture on how the intervention impacted the final outcomes for the twins. Although the same goals were not used for each of the boys in the case study, obtaining a baseline on their achievable goal before the intervention began would have a made the results more sound. 
The multiple baseline designs demonstrate the effects of an intervention by adding the intervention to baselines at different points in time. A clear effect is evident if performance changes when and only when the intervention is applied. However, one limitation for using this method to measure outcomes is if the baselines are interdependent so that implementation of treatment for one participant leads to the changes in other participants. For example, child one may discuss with their peers, after meeting with the researcher during baseline that she tried to write her last name. Child two or child three may then over hear and discuss letters of their last name with their peers or parents.

The parents of the WVU Nursery School are middle class and are very involved in their child's learning. Parents place a high value on education and participate in helping their children with various Nursery School activities at home. Parents learned about the Roy Moxley Project during a parent meeting in both January and August of 2009, and were very interested in encouraging their children to choose a goal. When parents received indications that their child was participating in a project, they took an active roll in helping their children practice at home. This did not occur with all children but children did use this technique to help them prepare for presentations. This may have allowed children to gain more knowledge through parent participation rather than step by step instruction with the researcher. 


\section{References}

Albertson, K., \& Shore, C. (2008). Holding in Mind Conflicting Information: Pretending, Working Memory, and Executive Control. Journal of Cognition and Development, 9(4), 390-410.

Retrieved from WVU Electronic Journals database.

Arnold, D. Zeljo, A., Doctoroff, G., \& Ortiz, C. (2008). Parent Involvement in Preschool: Predictors and the Relation of Involvement to Preliteracy Development. School Psychology Review, 37(1), 74-90.

Berk, L. E. \& Winsler, A. (1995). Scaffolding children's learning : Vygotsky and early childhood education. Washington, DC : National Association for the Education of Young Children.

Bodrova, E., Leong, D., Hensen, R., \& Henninger, M. (2000). Imaginative, Child-Directed Play: Leading the Way in Development and Learning. Dimensions of Early Childhood, 28(4), 25-30.

Bodrova, E., Leong, D., \& International Bureau of Education, G. (2001). Tools of the Mind: A Case Study of Implementing the Vygotskian Approach in American Early Childhood and Primary Classrooms. Innodata Monographs 7. Retrieved from WVU Electronic Journals database.

Brown, W. (2008). Young Children Assess Their Learning: The Power of the Quick Check Strategy. Young Children, 63(6), 14-20.

Dewey, J. (1916). Democracy and Education. An Introduction to the Philosophy of Education (1966 ed.). New York: Free Press.

Dewey, J. (1938). Experience and Education. New York: Collier Books, Macmillan

Dodge, D. T., Colker, L. J., Heroman, C. (2002). The Creative Curriculum: For Preschool. 4th Edition. Washington, D.C., Teaching Strategies.

Epstein, A. (2003). How Planning and Reflection Develop Young Children's Thinking Skills. Young Children, 58(5), 28-36. 
Hohmann, M., Weikart, D.P., (1995). Education Young Children: High/Scope Education Research Foundation. (pp. 168-181). Michigan: High/Scope Press,.

Hyson, M., ed. 2003. Preparing early childhood professionals: NAEYC's standards for programs. Washington, DC: NAEYC.

Katz, Lillian (2009). Intellectual Emergencies: Some Reflections on Mothering and Teaching. Louisville, NC: Kaplan Press.

Kazdin, Alan (1982). Single-Case Research Designs: Methods for Clinical and Applied Settings. New York: Oxford. Oxford Univsersity Press.

Lysyuk, L. G. (1998). The Development of Productive Goal Setting with 2-to 4- Year-old Children. International Journal of Behavioral Development, 22(4), 799-812. Retrieved from WVU Electronic Journals database.

Malaguzzi, L., (1998). History, ideas, and basic philosophy: An interview with Lella Gandini. In C. Edwards, L.Gandini, \& G. Forman (Eds.) The hundred languages of children: The Reggio Emilia approach-advanced reflections ( $2^{\text {nd }}$ ed., pp.49-97). Greenwich, CT: Ablex.

Marcovitch, S., Jacques, S., Boseovski, J. J., Zelazo, P.D., (2008). Self Reflection and the Cognitive Control of Behavior: Implications for Learning. International Mind, Brain, and Education Society and Wiley Periodicals, 2(3), 136-141. Retrieved from WVU Electronic Journals database.

Moran, M., \& Jarvis, J. (2001). Helping Young Children Develop Higher Order Thinking. Young Children, 56(5), 31-35. Retrieved from WVU Electronic Journals database.

Moxley, R., Rupich, L., Studwell, P., Gibson, B. (1983). Self-recording throughout the early childhood curriculum. The Pittsburgh Association for the Education of Young Child Journal. 
Moxley, R. \& Studwell, P. (1984). Self-Recording in Kindergarten: A Study in Naturalistic Evaluation. Psychology in the Schools, 21(4), 450-56.

Moxley, R., \& And, O. (1990). Improving the Instruction of Young Children with Self-Recording and Discussion. Early Childhood Research Quarterly, 5(2), 233-49.

Piaget, J. (1937). Principal factors determining intellectual evolution from childhood to adult life. In E.D. Adrian et al. (Eds.), Factors human behavior (p.32-48). Oxford, England: Harvard University Press.

Piaget, J. (1962). The Stages of the intellectual development of the child. Bulletin of the Meninger Clinic, 26, 120-128.

Skinner, B.F. (1948). Walden two. New York: Macmillan.

Skinner, B.F. (1953). Science and human behavior. New York: Macmillan.

Vygotsky, L. S. (1978). Mind in society: The development of higher psychological process. Cambridge, MA: Harvard University Press.

Warash, B., Kingsbury, D. (1988). The scrapbook project: A journal activity for young children. Journal of Language Experience. 9(1), 12-16.

Warash, B., \& Workman, M. (1993). All Life's a Stage; Children Dictate and Reenact Personal Experiences. Dimensions of Early Childhood, 21(4), 9-12.

Warash, B.G. (2001). Is It Contract Day? Association for Childhood Education International-Focus on Pre-K \& K. 13 (3), 4-7.

Warash, B., (2004). Getting Back To The Basics With Paper Dolls. Dimensions, 32(1), 10-15

Warash, B., Curtis, R., Hursh, D., \& Tucci, V. (2008). Skinner Meets Piaget on the Reggio Playground: Practical Synthesis of Applied Behavior Analysis and Developmentally Appropriate Practice Orientations. Journal of Research in Childhood Education, 22(4), 441. 
West Virginia Department of Education (2008). $21^{\text {st }}$ Century Learning Skills and Technology Tools Content Standards and Objectives for West Virginia Schools (2520.14). Retrieved from http://wvde.state.wv.us/policies/p2520.14_ne.pdf

West Virginia Department of Health and Human Resources (2004). West Virginia Early Learning Standards Framework: Content Standards and Learning Criteria for Pre-Kindergarten.

Retrieved from: http://www.wvdhhr.org/bcf/ece/earlycare/stateplan/07_09_ attachments/attachment_5.2_wvelsf.pdf

Wheldall, K., \& Panagopoulou-Stamatelatou, A. (1991). The Effects of Pupil Self-Recording of OnTask Behavior on Primary School Children. British Educational Research Journal, 17(2), 11327.

Whitin, D. (1997). Collecting Data with Young Children. Young Children, 52(2), 28-32 
Appendix A

Prior Initiation Sheet 
Appendix A Prior Initiation Sheet

Recorder:

Date:

Did child initiate any type of skill or project they wanted to do during the Fall 2008 semester?

\begin{tabular}{ll}
\hline \multicolumn{1}{c}{ Name (Pseudonym) } & Yes/No \\
\hline Amanda, what? \\
Amy \\
Catherine \\
Christopher \\
Cindy \\
Cameron \\
Diana \\
David \\
Eugene \\
George \\
Gwen \\
Hannah \\
Jamie \\
Jennifer \\
John \\
Kimberly \\
Kurt \\
Marshall \\
Monica \\
Patrick
\end{tabular}


Appendix B

Contract for Individual Skills 
Appendix B

\section{THE ROY MOXLEY PROJECT}

WVU Nursery School Contract for Individual Skills

Melissa:

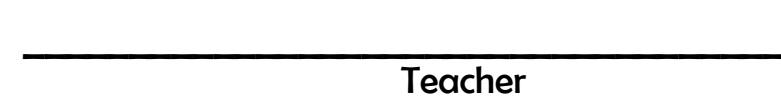

Date

Keri:

Date

Teacher

Bobbie:

Director

Date

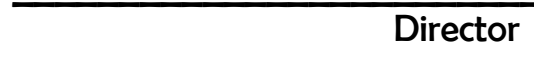

Skills to work on:

I, , agree to learn the above skill.

Child's Name:

Date: 
Appendix C

Self-Recording Chart 
Appendix C

Child's Self Recording Chart

Name:

Skills/Behaviors

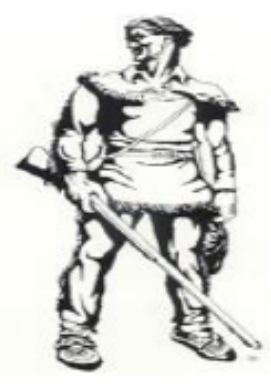

Dates
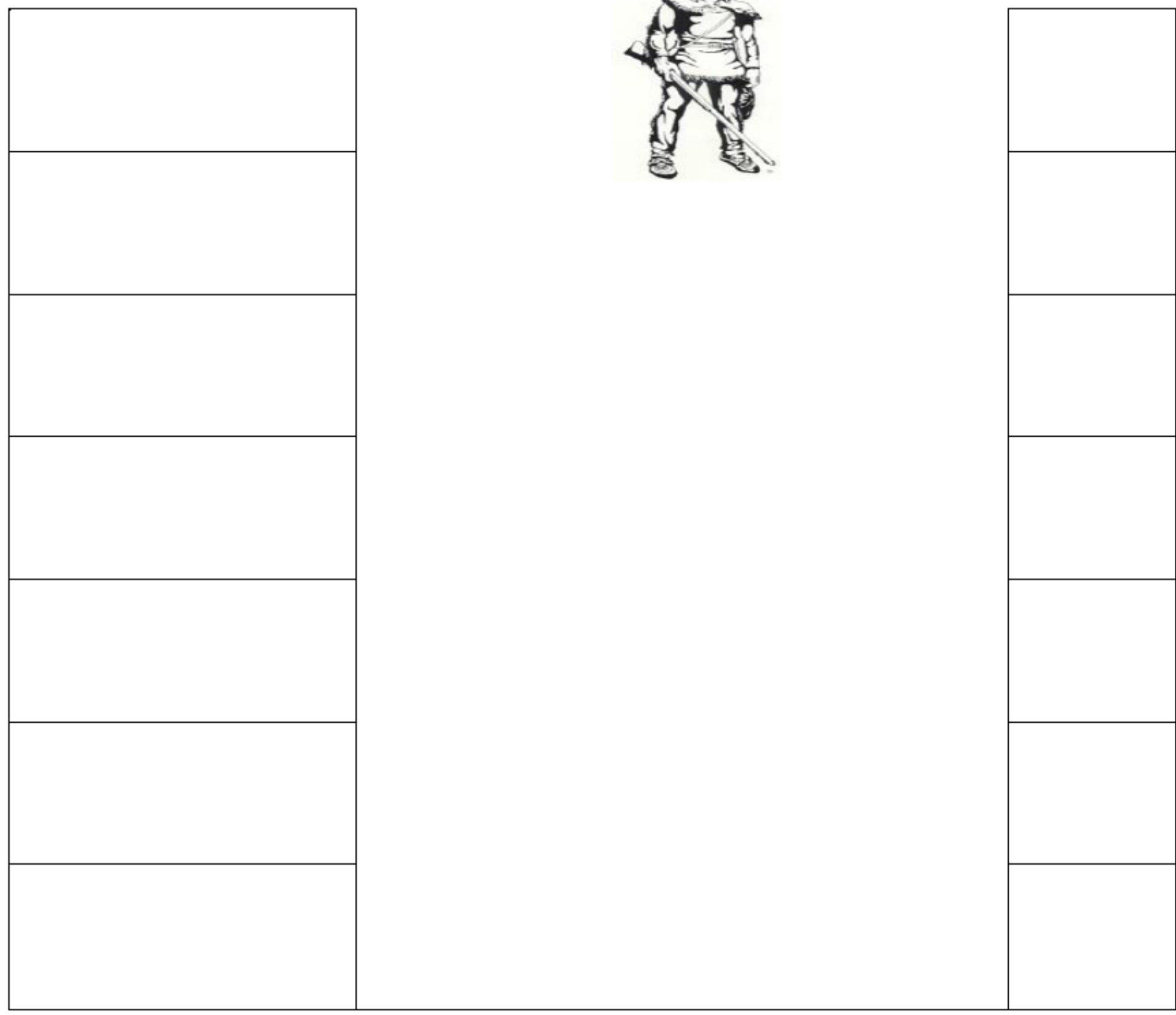

Individual Skill:

Teacher's Signature: 
Appendix D

Initiation/Outcomes Chart 
Appendix D

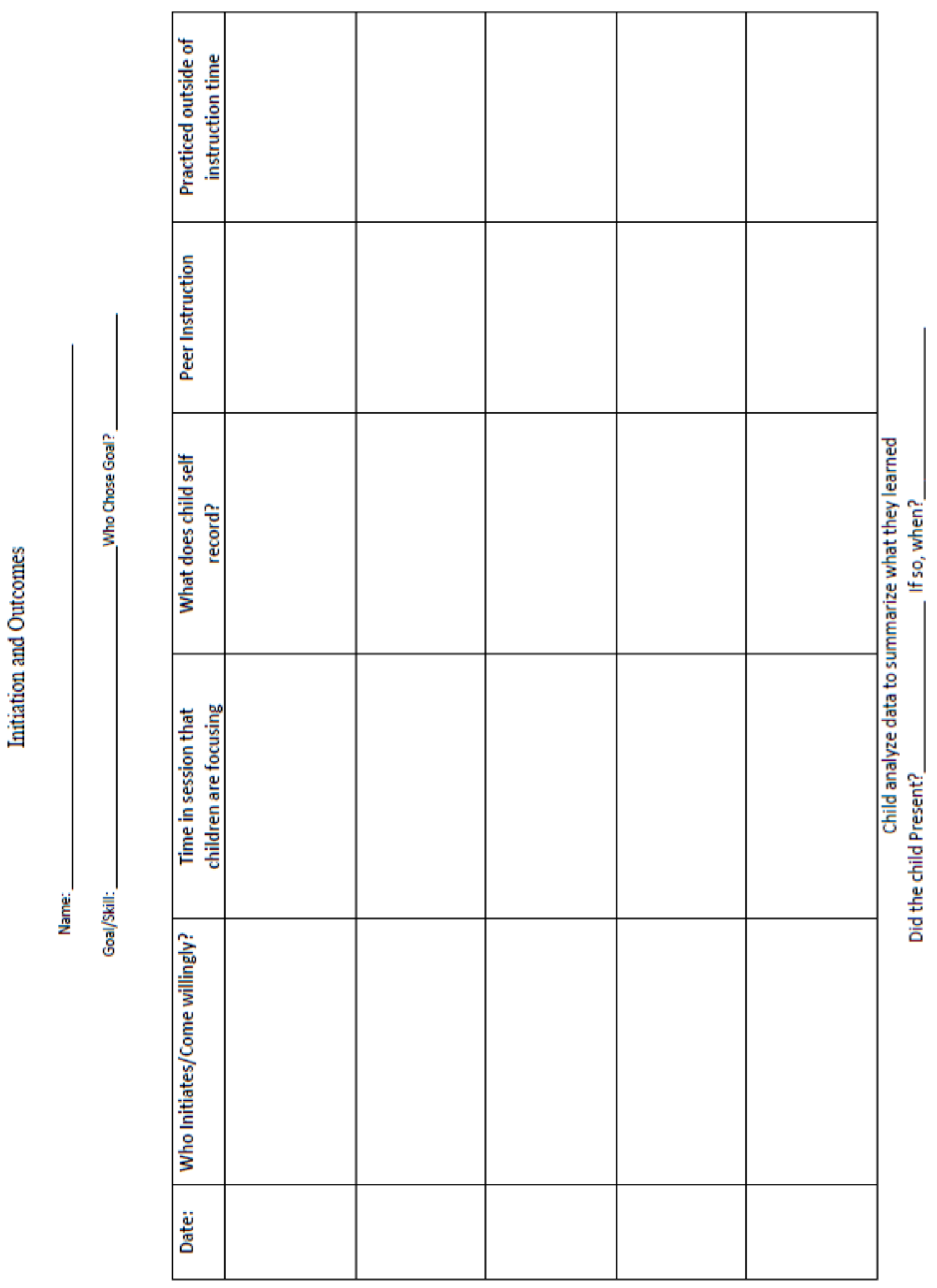


79

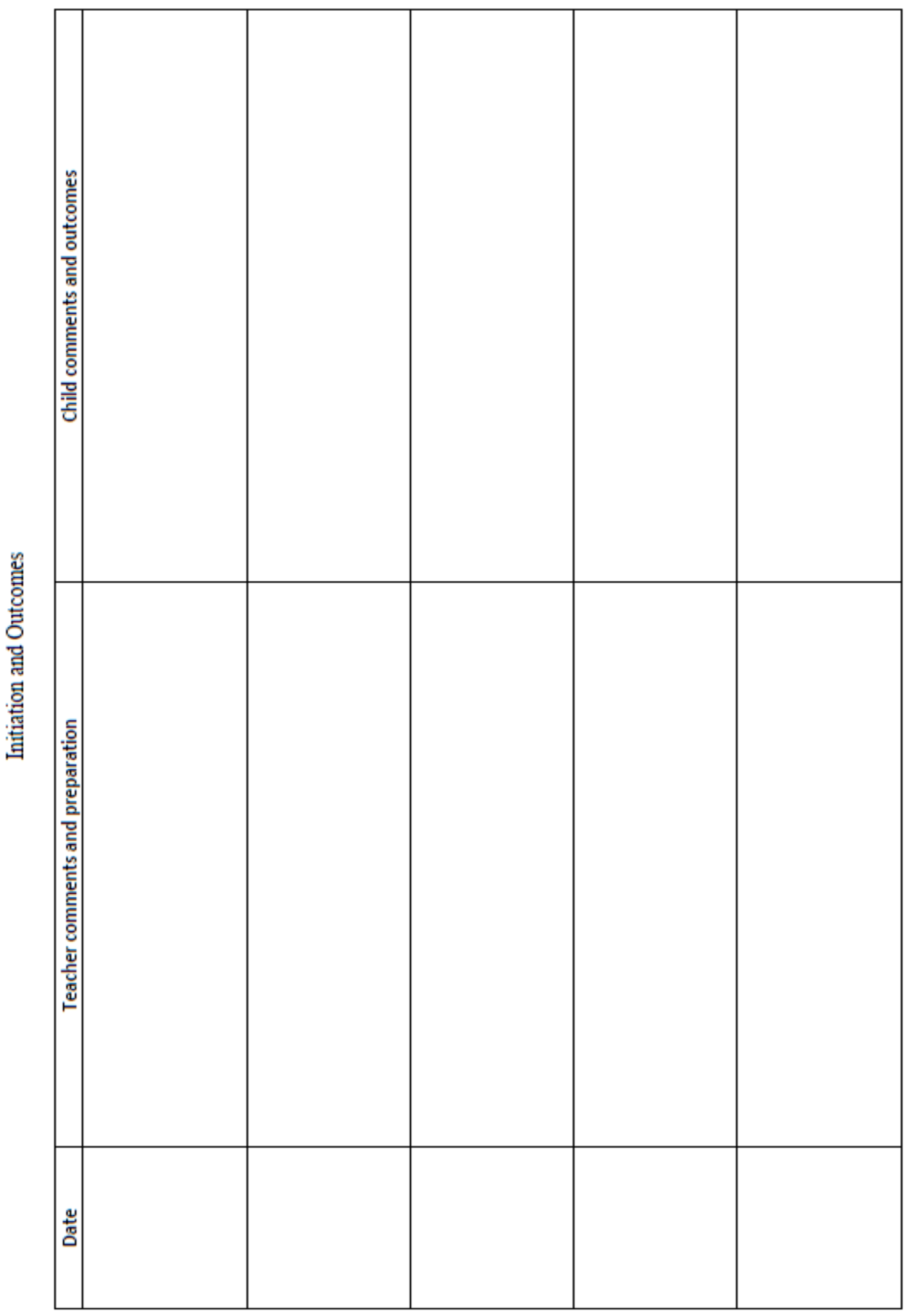


Appendix E

Certificate of Achievement 


\section{Certificate of Achievement}

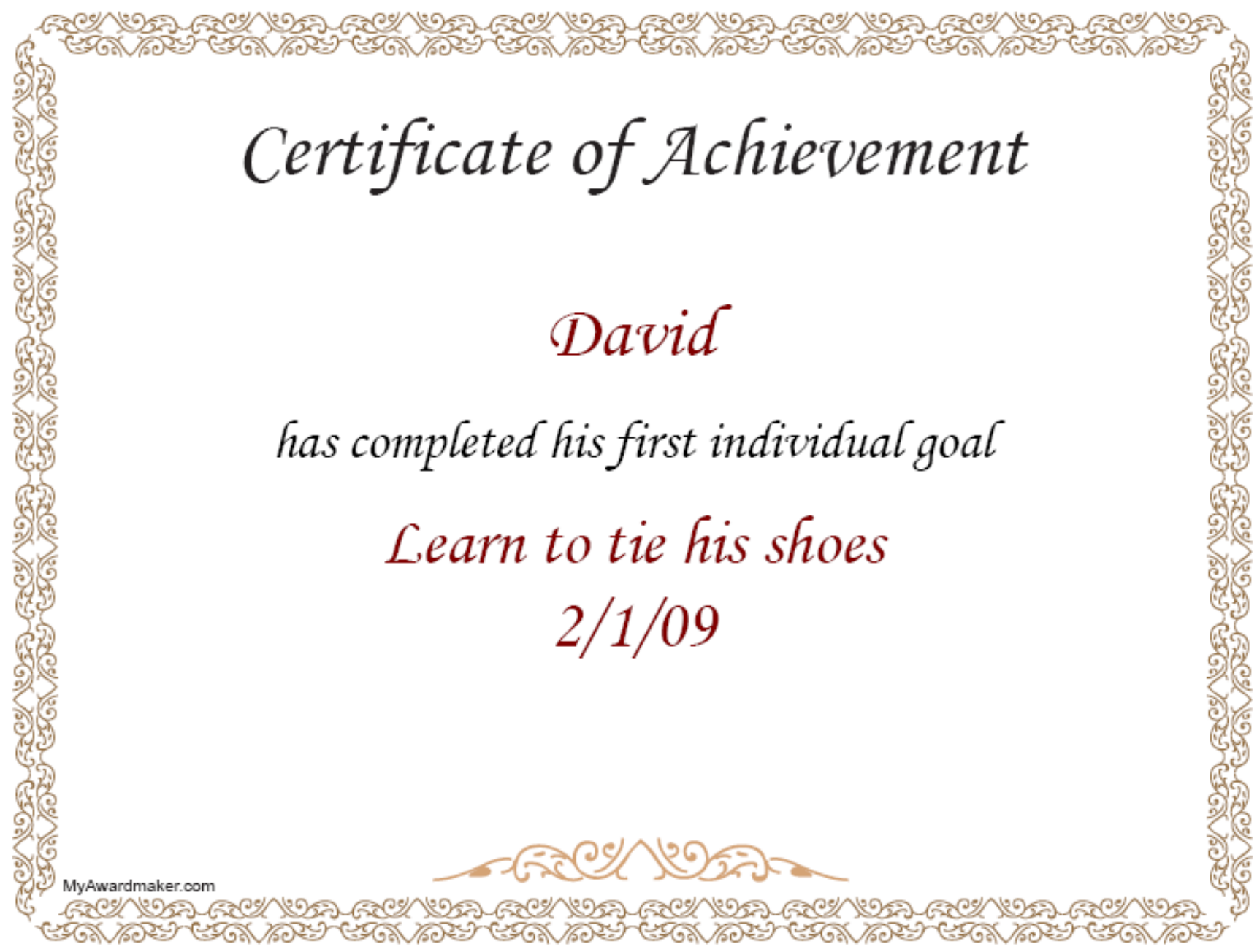

John H H.

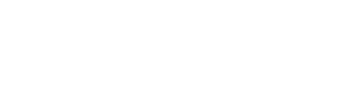

